\section{Ocean Engineering}

Vol. 33, Issues 11-12, August 2006, P. 1431-1461

http://dx.doi.org/10.1016/i.oceaneng.2005.10.015

(c) 2005 Elsevier
Archimer, archive institutionnelle de l'Ifremer http://www.ifremer.fr/docelecl

\title{
Assessment of wind-forcing impact on a global wind-wave model using the TOPEX altimeter
}

\author{
Hui Feng ${ }^{\mathrm{a}}$, Doug Vandemark $\stackrel{\underline{b}}{\underline{1}}{ }^{1}$, Yves Quilfen ${ }^{\mathrm{c}}$, Bertrand Chapron ${ }^{\mathrm{c}}$ and Brian Beckley ${ }^{\mathrm{d}}$
}

\author{
${ }^{a}$ Center for Atmospheric Sciences, Hampton University, Hampton, VA, USA \\ ${ }^{\mathrm{b}} \mathrm{NASA} / \mathrm{GSFC}$, Wallops Island, VA 23337, USA \\ 'IFREMER/Center de Breast, Plouzane, France \\ ${ }^{\mathrm{d}}$ Raytheon/ITSS, VA, USA \\ Corresponding author : hui.feng@unh.Edu
}

\begin{abstract}
:
The study presents assessment of an operational wave model (Wavewatch III), focusing upon the model sensitivity to wind-forcing products. Four wind fields are used to drive the model, including the NCEP/NCAR reanalysis and three other products that assimilate various satellite wind measurements having high spatial resolution, including the QuikSCAT scatterometer. Three wave field statistics: significant wave height, mean zero-crossing wave period, and mean square slope are compared with collocated TOPEX altimeter derivatives to gauge the relative skill of differing wind-forced model runs, as well as to demonstrate an extended use of the altimeter beyond simply supplying wave height for wave model validation and assimilation. Results suggest that model output is critically sensitive to choice of the wind field product. Higher spatial resolution in the wind fields does lead to improved agreement for the higher-order wave statistics
\end{abstract}

Keywords: Wave modeling; Altimeter;Scatterometer; Wind forcing; Sea state bias 


\section{Introduction}

There is a cm-scale range bias induced by ocean surface waves in all satellite altimeter sea level measurements, the so-called sea state bias (SSB). This is the largest remaining source of error in altimeter range measurements. Thus, improved SSB correction is a critical and desired goal for accurate sea level estimation. Recent theory (Chapron et al., 2001; Elfouhaily et al., 1999, 2000) and observations (Millet et al., 2003a, b; Melville et al., 2004) suggests that long wave orbital velocity and short-scale surface wave slope variances, related to the second and fourth-order moments of a given wave spectrum, directly drive the SSB and its variability. The current operational SSB correction model (Gaspar et al., 2002) relies on two parameters available directly on board: the altimeter-derived wind speed and significant wave height. Though effective, the twoparameter SSB models are limited because 1) the altimeter-derived wind speed is not uniquely mapped to the in situ wind; it also depends on the overall sea state (Gourrion et al. 2002a, 2002b) and, 2) the utilization of wind speed and wave height, even if they are "accurate”, does not parameterize the bias physically. One means to deal with these issues for a refinement in the future SSB models is to obtain more reliable wind measurements such as by scatterometry. Another is to obtain measurements of higher-order ocean wave statistics associated with the long wave nonlinearities that drive the bias. One potential means to gain the latter is through a wind wave model (e.g. Kumar et al., 2003).

Continual advances in ocean wave modeling have resulted in the community standard 3rdgeneration model (Komen et al., 1994). Numerical implementation has entered a stage where practical basin- and global-scale hindcast modeling has evolved under such frameworks as WAM (WAMDI Group, 1988; Komen et al., 1994) and WaveWatch III (Tolman, 2002; Tolman et al., 2002); models capable of routinely rendering full two-dimensional ocean wave spectra. One motivation for this work is to explore the potential for applying these spectral predictions to the SSB correction.

Winds blowing over the sea surface are a direct cause of surface wave generation. Intuitively, the quality of the wind forcing used to drive a wave model is a critical first-order control upon the wave model outcome. As clearly demonstrated by Cavaleri et al. (1994), the empirical relation between significant wave height $\left(H_{s}\right)$ and wind speed square $\left(U_{10}{ }^{2}\right)$ for a fully-developed wind sea shows that error in $H_{s}$ is amplified relative to error in $U_{10}$. The sensitivity of wave model prediction to variations in wind forcing fields has been studied by several researchers (Ponce and OcampoTorres, 1998; Bauer and Weisse, 2000; Abdalla and Cavalla, 2002; Moon et al., 2003). These studies indicate that use of higher-frequency winds to force the wave model yields positive output impact, particularly in the sense of significant wave height. In short, without high quality wind forcing fields, wave model results may suffer even given the correct physics. Furthermore, one can speculate that the quality of wind forcing fields becomes even more critical when considering higher-order wave spectral moments because these terms are more directly associated with shorter waves and hence tied more strongly to the wind forcing.

This study assesses the global wave model sensitivity to forcing by wind fields enhanced using satellite data. This will be done through contrast with a model run forced using nonassimilating meteorological model wind fields. One study focus is the evaluation of the high-order wave spectrum moments estimated from global wave model output; the driver being altimeter sea state bias correction needs. The study also sets out to demonstrate a new approach for using altimeter capabilities to validate the modeled wave field parameters. The approach extends model evaluation beyond the nominal significant wave height $H_{s}$ (the total wave spectral energy) comparison to investigate the wind sea and wave spectrum's high frequency tail via the zero- 
crossing period and slope variance. Such an approach should prove useful in efforts to address dissipation formulations within the spectral balance equation in the wave model physics.

An open source operational surface wind-wave model WaveWatch III (WW3) is selected for this work. The WW3 model is forced using four different wind fields, estimating the wave field parameters from the directional spectra in hindcast mode for the whole of year 2000. All WW3 model parameters, wind fields, and altimeter data are then collocated on the altimeter TOPEX altimeter ground tracks. Assessment includes global and regional intercomparison of the modeled wave parameters. Wave model accuracy is evaluated in part by comparing modeled wave parameters with TOPEX observations. The paper is organized as follows. WW3 model implementation is described briefly in Section 2.1. The selected wind fields and data compilation are given in Sections 2.2 and 2.3, respectively. The altimeter estimates for model evaluation are described in Sections 2.4-2.5. Results are presented in Section 3. Section 4 provides discussion and conclusions.

\section{Methodology}

\subsection{Wave model: WW3}

The wave model WaveWatch III (WW3) is a full third-generation ocean wind wave model. It was developed at the National Oceanic and Atmospheric Administration/National Center for Environmental Prediction/National Weather Service (NOAA/NCEP/NWS) (Tolman, 2002; Tolman et al., 2002) retaining characteristics of the well-known WAM model, and has been run operationally by numerous operational and research centers. It solves the spectral action density balance equation for wavenumber-direction spectra with the full nonlinear physics (Tolman and Chalikov, 1996) for modeling the evolution of the directional wave energy spectra used to estimate mean wave field parameters. The source and sink terms in WW3 were adjusted and validated using ERS-2 altimeter and ocean buoy $H_{s}$ data (Tolman, 2002). In our application, WW3 was run on a $1^{\circ}$ by $1^{\circ}$ grid over the global domain from $70 \mathrm{~S}$ to $70 \mathrm{~N}$ in latitude with model outputs generated every six hours for the entire year 2000. The wave spectrum is resolved (i.e. the wave-number grid ) into 24 azimuthal direction bins and 25 frequency bins logarithmically spaced from $0.042 \mathrm{~Hz}$ to $0.405 \mathrm{~Hz}$ with intervals of $\Delta \mathrm{f} / \mathrm{f}=0.1$.

Four different time steps are set to reach computational efficiency as suggested by Tolman (2002) for global applications. The global time step is set to 3600s at which the entire solution is propagated. This also defines the maximum time step in the model source term integration. The minimum time step in the source term integration is set to 300s (a number that depends on the stability properties of the numerical scheme). The maximum propagation time step is set to $900 \mathrm{~s}$ for the longest wave components in the spectrum. The refraction time step set to 3600s.

Wind forcing fields were obtained from four different sources (see Section 2.2), updated 6hourly at all model grid points. Sea ice concentration data come from the product derived from NIMBUS-7, SMMR, and SSM/I data using the NASA Team algorithm (Cavalieri et al., 1984) and are updated daily in all grid points. The WW3 model treats a grid point with more than 33\% in ice concentration as land. The wave model was initialized over a seven day period to arrive at a stationary model output, and then run for the entire year of 2000. The model run contains no assimilation of altimeter or buoy wave height observations.

\subsection{Wind forcing fields}

As discussed, the quality of the wave parameters estimated via WW3 spectra likely depends on the quality and resolution of the wind forcing fields. This study uses four different wind products (Table 1) to drive the wave model WW3. Two numerical meteorological center wind field analyses were selected. The first is the wind field product from the NCEP/NCAR reanalysis 
atmospheric model. This reanalysis utilizes a three dimensional (3-D) variational analysis scheme (Kalnay et al., 1996; Kistler et al., 2001) with various meteorological observations assimilated. No satellite-measured winds were assimilated in the year 2000. The 10-meter wind components are available every six hours with a spatial resolution of $1.875^{\circ}$ in longitude and about $1.900^{\circ}$ in latitude. This wind field product was selected because 1) it is similar to the wind field used to develop the version of the WW3 (Tolman, 2002) and, 2) we use the modeled waves driven by the NCEP/NCAR wind as a baseline for comparisons to those driven by the other wind fields, for example, those enhanced by satellite-measured winds as described in the following.

The second meteorological analysis wind field is from the European Center for MediumRange Weather Forecasts (ECMWF). ECMWF used a four dimensional (4-D) variational assimilation scheme to assimilate various meteorological observations as well as ERS-1/2 scatterometer winds (Rabier et al., 2000; Isaksen and Janssen, 2004). Isaksen and Janssen (2004) show that assimilating ERS scatterometer data into the ECMWF system has a positive impact on the analysis and forecasting of ocean waves. One strength of the ERS scatterometers is the absence of rain contamination at C-band and the data quality is thus consistent, but a weakness is its narrow swath and hence limited spatial coverage. For this product, six-hourly wind component fields are available with the spatial resolution of $1.125^{\circ}$ by $1.125^{\circ}$.

The third is an enhanced wind field product derived through a spatial blending of the highresolution scatterometer (QuickSCAT) wind observations with the NCEP/NCAR reanalysis winds (Chin et al., 1998; Milliff at al., 1999). The essence of this wind field is that it contains the highwavenumber (spatial) information from QuickSCAT measurements. The blending scheme retains the QuickSCAT wind measurements in its swath regions and enhances the NCEP/NCAR fields in QuickSCAT sampling gaps through imposition of high-wavenumber content that is based on monthly local QuickSCAT statistics. The swath of the QuickSCAT SeaWinds is three times wider than that of ERS, and hence this product has more highly-resolved spatial information. Rain can contaminate the quality of QuickSCAT wind retrievals (Milliff et al., 2004) to some degree. The 6hourly wind component data are available globally in a $0.5^{\circ}$ by $0.5^{\circ}$ grid.

The last product is an enhanced ECMWF wind field obtained by assimilating Special Sensor Microwave/Imager (SSM/I)-retrieved wind speeds. SSM/I is a passive microwave sensor capable of retrieving ocean surface wind speeds through the response of the microwave emissivity to the ocean surface roughness but without wind direction information. Advantages of using SSM/I include long-term availability, accurate wind magnitudes, and good global coverage in space and time. A two dimensional (2-D) variational analysis method (VAM) is used to combine information from ECMWF 10m surface wind components with the more highly-resolved SSM/I wind speeds (Atlas et al., 1996). The 6-hourly wind component data are available in a $1^{\circ}$ by $1^{\circ}$ grid between $78 \mathrm{~S}$ and $78 \mathrm{~N}$ in latitude.

\subsection{Collocation of wave model and altimeter products}

Four wind fields, WW3 model-estimated wave field parameters, and altimeter TOPEXderived data have been collocated by spatial and temporal interpolation onto the standard NASA/GSFC altimeter pathfinder sampling locations (Koblinsky et al., 1998). The collocation results in over 1.5 million composite data records for the year 2000. The coincident TOPEX and WW3 model wave field parameters used in this study are summarized in Table 2.

\subsection{Model evaluation tools using altimeter and buoy-derived observations}

Assessment of wave model estimates needs special consideration, particularly concerning the higher-order wave spectrum moments of interest in our application. Operational centers and most 
wave model studies focus mainly on significant wave height, and occasionally on wave period, in model validation, assessment, and assimilation (e.g. Bidlot et al., 2002). Recall that the calibration and validation of the WW3 model version used here, and at NOAA/NCEP/NWS, are based strongly on significant wave height observations (Tolman, 2002).

Global altimeter coverage of the surface wave field points to the altimeter as a valuable tool for model output assessment at global to basin scales. Our model runs assimilate no surface wave observations and thus the altimeter data can be considered an independent source. In addition to the precise TOPEX-measured significant wave heights, methods have been developed in this study to estimate two other statistical measures. Several recent studies have used coincident satellite altimeter and in-situ buoy wave measurements to develop operational algorithms. Gourrion et al. (2002b) have shown that C-band radar cross section $\sigma_{c}$ measured using TOPEX and Jason-1 altimeters can be combined with altimeter-derived wave height $H_{\text {salt }}$ to estimate the mean square slope (mss), or slope variance. Under a linear gravity wave dispersion assumption this can be directly obtained from the wave acceleration variance $\left(m_{4}\right)$. The relation between $\mathrm{m}_{4}$ and $m s s$ is given in Table 2. In the development of the altimeter-based mss algorithm, they first calculated the buoy-based mss by a wave energy spectral integration up to a frequency cutoff at $0.4 \mathrm{H}_{s}$, a cutoff matching that used in our WW3 model calculations. With a large dataset of collocated National Data Buoy Center (NDBC) buoy and altimeter TOPEX observations, a neural network-based algorithm was constructed to estimate the mss of the wave field using C-band radar cross section $\sigma_{c}$ and altimeter-derived ("true") wave height $H_{\text {salt }}$ as

$$
m_{\text {slt }}=\mathrm{FNN} 1\left(\sigma_{c}, H_{\text {salt }}\right)
$$

With a similar methodology, an altimeter algorithm was recently developed (Quilfen et al.,2004) to infer the mean zero-crossing surface wave period by using altimeter Ku-band and C-band radar cross sections (i.e. $\sigma_{k u}$ and $\sigma_{c}$ ], the altimeter-derived wave height $H_{\text {salt }}$ and wind speed $U_{10 a l t}$ :

$$
T_{\text {zalt }}=\operatorname{FNN} 2\left(\sigma_{K u}, \sigma_{c}, H_{\text {salt }}, U_{10 a l t}\right)
$$

In addition, Gourrion et al. (2002a) also reported a neural network algorithm for altimeter-derived wind speed $U_{10 a l t}$ in terms of Ku-band radar cross section $\sigma_{k u}$ and altimeter wave height $H_{\text {salt. }}$

These altimeter algorithms have been adopted in this study as wave model evaluation tools. The three wind-wave parameters $m_{s s_{a l t}}, T_{\text {zalt }} U_{10 a l t}$ plus altimeter-measured wave height $H_{\text {salt }}$ were assumed as ground truth and compared with their counterparts estimated from the WW3 model driven by the four wind forcing fields for model performance evaluation.

\subsection{Statistical evaluation: error analyses}

Various statistical measures, mean error (bias), root mean square error (RMSE), scatter-index $(S I)$, and Pearson correlation coefficient $(r)$, are used to assess wave model performance by comparing the WW3-modeled wave field parameters against the corresponding altimeter-derived observations, computed as

$$
\begin{aligned}
& \text { Bias }=\frac{1}{n} \sum\left(M_{i}-A_{i}\right) ; \\
& R M S A=\frac{1}{n} \sqrt{\sum\left(M_{i}-A_{i}\right)^{2}} ;
\end{aligned}
$$




$$
\begin{aligned}
& S I=\frac{R M S E}{\bar{A}} ; \text { and } \\
& r=\frac{\sum\left(M_{i}-\bar{M}\right)\left(A_{i}-\bar{A}\right)}{\sqrt{\sum\left(A_{i}-\bar{A}\right)^{2}} \sqrt{\left(M_{i}-\bar{M}\right)^{2}}}
\end{aligned}
$$

where $A_{i}$ and $M_{i}$ indicate altimeter-observed and WW3-modeled wave parameters, respectively; $\bar{A}$ and $\bar{M}$ are their corresponding mean values; $\mathrm{n}$ is the sample number. In addition, we also make use of scatter and probability density function (PDF) plots and spatial analyses. In order to understand characteristics of the modeled wind-wave fields at both the global and regional scales, distinct regions representative of different wind-wave climates have been defined. Table 3 provides the geographical coverage definitions.

\section{Results}

For convenience, shorthand symbols are used thereafter to represent WW3 model-derived products driven by different wind field products. WW3-NN, WW3-QN, WW3-EE and WW3-ES will indicate the WW3 model products driven by NCEP/NCAR reanalyzed winds, QuickSCAT and NCEP blended winds, ECMWF winds enhanced with ERS scatterometer, and ECMWF winds enhanced with SSM/I radiometer, respectively.

\subsection{Spatial structure differences amongst four wind-forced model outputs}

One immediate interest is to look at the difference between wind forcing fields and the resulting wave model fields. First, we present the global wind forcing fields being used for driving the WW3 model and the WW3 model responses to develop a general understanding for the sensitivity of the wave model responses to variations in the wind field products.

Fig. 1 depicts three global mean wind speed fields for a particular time period (Jan, 2000). Compared with the NN winds (Fig. 1b), the QN blended winds (Fig. 1a) show more spatial content, significantly sharpening the spatial scales of the wind frontal structures as determined by the highly spatially resolved QuickSCAT measurements. In the difference map shown in Fig. 1c (the QN wind minus the $\mathrm{NN}$ wind), $\mathrm{NN}$ winds are remarkably weaker in the equatorial regions with a negative difference around $2-3 \mathrm{~m} / \mathrm{s}$. In the higher latitudes, the difference is relatively low at about $1 \mathrm{~m} / \mathrm{s}$ over most of the region but is larger at small scales. In the Southern ocean and southern Indian ocean, weaker QN winds are observed, and the difference exceeds $1 \mathrm{~m} / \mathrm{s}$. In most of the coastal regions, stronger QN winds are observed.

How does the wave model respond to these variations in forcing fields? To distinguish between the windsea and the swell within the total significant wave height, we have isolated these two wave modes within each modeled directional wave spectrum by a simple spectral partitioning algorithm following Hanson and Phillips (2001). Fig. 2a-c depicts the global difference maps of the WW3-QN minus WW3-NN of wave height $H_{\mathrm{s}}$, swell height $s H_{\mathrm{s}}$ and windsea height ${ }^{2} H_{\mathrm{s}}$, respectively. The spatial pattern of the swell height $s H_{s}$ difference (Fig. 2b) is generally similar to that of significant wave height $H_{s}$ difference (Fig. 2a). This suggests that the positive model $H_{s}$ bias in WW3-QN is due mainly to the swell. The spatial pattern of the windsea $w H_{\mathrm{s}}$ difference corresponds closely to those of the wind and mss differences (Fig. 1c and Fig. 3c, respectively).

Fig. 3 shows the corresponding mean maps of WW3-modeled mss. Their patterns are generally similar to the spatial characteristics of the wind fields (Fig. 1), but the sharpness of the mss spatial structures shown in the WW3-QN mss becomes smoothed, most likely due to the windintegrating effect carried within the wave model physics. The significantly lowered mss in the 
WW3-NN for the equatorial regions (Fig. 3c) can be explained mainly by difference in wind forcing (Fig. 1c). The changes in spatial dynamics are clear and indicate that the scatterometerenhanced wind forcing leads to wave model response with higher spatial resolution.

Model wave field parameters are evaluated in further details using the altimeter-derived parameters. Fig.4 demonstrates an example where the altimeter-observed and WW3-modeled wave parameters as well as the forcing winds are compared directly along a satellite ground track. This documents a typical case of strong wave height gradient along a TOPEX ground track in the Eastern Equatorial Pacific region, an event during which a strong wind was blowing over a background swell with swell height $\mathrm{sH}_{s}$ around $1.7 \mathrm{~m}$. The result indicates that meteorological model NN winds smear high wave number information while the other three wind products retain a highly-varying spatial structure to some degree. It is clear that the TOPEX-observed wave field parameters $\left(H_{\text {salt }}\right.$ and $\left.m s s_{a l t}\right)$ exhibit spatial oscillations at finer spatial scales not captured in the WW3-NN wave field. But these finer scale changes are evident in the other three wind-driven WW3 model outputs to some degree with the highest match between the WW3-QN wave parameters and altimeter observations. It should be pointed out that in each of the latter three wind forcing (i.e. QN, EE and ES) satellite measurements with high spatial structures were blended or assimilated to different degrees, each exhibiting more highly-resolved spatial dynamics than in the NN wind.

To summarize, it is these highly-resolved wind forcing fields that drive spatial variability in the WW3 model wave field, particularly in the wave mean square slope ( $m s s)$ that does co-vary with the TOPEX-measured sea surface height anomaly (ssha), perhaps indicating sea level error associated with the sea state bias.

In the following two sections, we provide detailed evaluation of model performance by examining the difference between WW3 model wave field parameters and TOPEX estimates at both global and selected regional scales.

\subsection{Evaluation: global analysis}

A global view of comparisons between parameter PDFs is displayed in Fig. 5, including the six wind wave parameters of windspeed $U_{10}$ (a), wave height $H_{s}(\mathrm{~b})$, swell wave height $s H_{s}(\mathrm{c})$, windsea height $w H_{s}(\mathrm{~d})$, zero-crossing wave period $T_{z}(\mathrm{e})$ and mean wave square slope mss (f). Globally, the NN wind speed has an overall negative bias in comparison with the TOPEX-derived and the QN wind speeds, and the PDFs of the EE and ES winds fall between the NN and QN winds (Fig. 5a; Table 4). Another insight into the performance in the WW3 model parameters can be revealed by looking at the error statistics as a function of the TOPEX-observed parameters. In Fig 8(a-b), the error statistics of Bias and SI due to the wind forcing are given for the global dataset. Wind speed biases are negative below, and then positive above, a wind speed of about 5 $\mathrm{m} / \mathrm{s}$ for all the wind products, respectively. Clearly, the NN winds have the largest Bias and SI while the QN blended winds give the least. However, the WW3-NN $H_{s}$ ( as well as WW3-EE $H_{s}$ ) accords very well with the TOPEX-measured wave height $H_{\text {salt }}$ (Fig. $5 \mathrm{~b}$ ) in PDFs over most of the $H_{s}$ range except in the high $H_{s}$ region $\left(H_{s}>5\right)$ where Bias appears negative (Fig. 9a). It is most likely because our version of the WW3 model was adjusted and validated in terms of a global run driven by a wind forcing field whose statistical characteristics are similar to that of the NN and EE wind fields. Interestingly, the WW3-QN $H_{s}$ generated by the Qscat/NCEP blended wind, which has the least uncertainty and is usually considered closer to the surface wind truth, has a systematic and highest positive Bias against $H_{\text {salt }}$ over most of the wave height range but has relatively low $S I$ value (Fig. 9a-b). This finding is consistent with the report of Rogers and Wittmann (2002). Among the four WW3 model $H_{\mathrm{s}}$, the WW3-EE $H_{\mathrm{s}}$ gives the best performance overall (Table 4). 
We also took a close look into the details of which wave field component (swell or wind sea) controls this positive Bias in the WW3-QN $H_{s}$. The WW3-QN $s H_{s}$ has a strong positive Bias with respect to the other three WW3 model $\mathrm{sH}_{\mathrm{s}}$ (Fig. 5c). The WW3 model (both WW3-QN and WW3ES) windsea $w H_{s}$ are biased slightly high with respect to the other two products (Fig. 5d). This again implies that the positive Bias in the total wave energy $H_{s}$ is associated likely with a model swell overestimate that in turn comes from the high frequency contained wind fields.

The WW3 model zero-crossing wave periods estimated by four distinct winds accord fairly well each other, but show a consistent positive Bias in the distribution mode with respect to the altimeter-derived $T_{\text {zalt }}$ (Fig. 5e). Fig. 10(a-b) illustrates another view of the error statistics in model $T_{z}$ with respect to $T_{\text {zalt. }}$ A discrepancy between the WW3 model $T_{z}$ and altimeter-derived $T_{\text {zalt }}$ can be identified about a critical period value ( $~=7-8$ second) beyond and below which the WW3 model periods are under- and over- estimated, respectively. Overall, the best performance among the four WW3 model products of $T_{z}$ is WW3-ES $T_{z}$ and the worst is for WW3-QN $T_{z}$ (Table 4).

The distributions of the mean square slope (mss) shown in Fig. $5 f$ exhibit more complicated and distinctive patterns. The expectation that this high-order statistics of the wave field follows the wind distribution appears to be true. In general, the distribution patterns of the WW3-QN and WW3-ES mss are most consistent with that of mss $_{\text {alt }}$ derived from Eq.1 among the four WW3 model mss products. Fig.11 (a-b) illustrates the statistical error patterns of the WW3 model mss values as a function of TOPEX-measured mss $_{\text {alt }}$. The WW3-QN and WW3-ES mss give very low bias and $S I$ values in the relatively low mss region $(m s s<0.01)$ where the other two mss products are biased low. However, all WW3 model mss products appear negatively biased beyond the critical value of mss $=0.01$. The $S I$ values in all the four mss products become higher beyond that as well. Among the four WW3 model products, the WW3-QN mss clearly shows the best performance in terms of the error statistics (Table 4).

\subsection{Evaluation: regional analysis}

Results presented to this point reflect the global data set. Regional analyses are detailed next in order to gain a further understanding of the wave model difference characteristics.

In Fig. 6, a distribution intercomparison of the six wind wave field parameters is illustrated for the region of the Northern Ocean as defined in Table 2. General patterns of the wind field and error statistics are quite similar to the global view. But some distinct features are observed in this region. For the wind speeds, there are the lowest and highest Bias and SI for the QN and NN winds (Fig. 8c-d, Table 4), respectively. Similar to what is seen in the global analysis, the WW3QN $H_{s}$ has a high positive bias over the significant wave height $H_{s}$ range up to $H_{s}=6 \mathrm{~m}$, but this positive bias appears decreased beyond $H_{s}=6 \mathrm{~m}$ while the other three WW3 $H_{s}$ values appear biased negative after that.

The distributions of the WW3 model $H_{s}$ products (Fig. 6) are fairly consistent with each other, particularly for the high sea state conditions. This model agreement suggests that in the regions with strong winds the WW3 model performs consistently regardless of the wind field choice, both for the total wave height and for the higher-order moments (weighted toward the spectral tail). In other words, the wave model response to wind forcing is driven mainly by wind magnitude rather than spatial/temporal forcing field differences, in the high latitudes.

Once compared with the altimeter-derived $T_{\text {zalt }}$ and $m s s_{\text {alt }}$, distinct patterns of the WW3 model vs. altimeter $T_{\text {zalt }}$ and msS $_{\text {alt }}$ are easily distinguished from the global view. The distribution mode of the WW3 model $T_{z}$ is quite consistent with that of the TOPEX-derived $T_{\text {zalt }}$ (Fig. 6e). The WW3 $T_{z}$ Bias and SI as a function of the TOPEX-measured $T_{\text {zalt }}$ are given in Fig. 10(c-d). A critical period ( 7-8 seconds) is still recognized beyond and below which the WW3 model $T_{Z}$ becomes underestimated and overestimated, respectively, by using $T_{\text {zalt }}$ as a reference. This is 
generally consistent with what is seen in the global view in Fig. 10(a-b). But the WW3 modeled $T_{z}$ shows a better performance in this region than in the global case. The four products of the WW3 model mss match each other well as does mss alt (Fig. 6f). The WW3-modeled mss Bias and SI given in Fig.11(c-d) show that the WW3-QN mss are slightly overestimated in the region of mss < 0.01 beyond which, however, all the WW3 model estimates of mss become underestimated and the SI values become higher. Overall, the WW3-QN mss gives the best performance (Table 4).

The most significant inconsistency between the WW3-modeled and altimeter-observed parameters is seen in the Eastern Equatorial Pacific (Fig. 7, Figs 8-11(e-f), Table 4). The QN winds (as well as ES and EE winds) match the TOPEX-measured wind $U_{10 a l t}$ well but are much higher than the NN winds (Fig. 7a). The WW3-QN $H_{s}$ has a strongest positive bias relative to the $H_{\text {salt }}$ (Fig. 7b; Fig. 9e), and this positive bias is predominately due to the swell components (Fig. 7c). However, the WW3-NN $H_{s}$ again matches $H_{\text {salt }}$ very well (Fig. 7b, Fig. 9e-f).

The WW3 model $T_{z}$ products are all biased positively with respect to altimeter-derived $T_{\text {zalt }}$ (Fig. 7e). Among the four WW3 model $T_{z}$ products, the WW3-ES and WW3-NN $T_{z}$ show the best and worst performance, respectively, in this region (Fig. 10e-f, Table 4). In Fig. 7f and Fig. 11e-f, the results are shown for the WW3 model mss. The WW3-QN mss again accord best with the altimeter-derived mss $_{\text {alt }}$ while the WW3-NN mss is consistently biased low.

\section{4. wind dependence of mean square slope mss}

The nature of the wind-driven sea surface roughness can be further investigated by viewing the WW3 model mss against wind speed. Fig.12 illustrates an inter-comparison of the WW3modeled estimates of mss and the altimeter-derived $m_{s s_{a l t}}$ as a function of wind speed $U_{10}$ for the two selected extreme cases of the WW3-QN and WW3-NN.

At the high latitude regions (i.e. the Northern and Southern Oceans), the wind-dependent mss patterns of the two WW3 model products (WW3-QN and WW3-NN) agree well (Fig. 12b) are generally consistent with the global mss pattern (Fig. 12a). The WW3 model mss is overestimated at the lower winds (below $U_{10}<4 \mathrm{~m} / \mathrm{s}$ ). It is worth pointing out that this wind speed domain ( $<$ $4 \mathrm{~m} / \mathrm{s}$ ) is not within the dominant distribution mode in this region (Fig. 6a) while for typical wind range $(5-12 \mathrm{~m} / \mathrm{s})$ the WW3-modeled mss values are consistent very well with mss $_{\text {alt }}$. By contrast, remarkable deviations between the two model mss products are apparent in the Eastern Equatorial Pacific region (Fig. 12c) where both wind speeds and wave heights are significantly lower than those in the high latitudes. Particularly, the dominant mode of wind speeds in this region falls around 4-6 m/s (Fig. 7a) and this is the point of the most significant discrepancy between the WW3QN and WW3-NN mss patterns seen in Fig. 12c. The WW3-NN mss is substantially lower than the WW3-QN mss. The latter agrees with the mss $_{\text {alt }}$ fairly well although it is still underestimated.

\subsection{SSB evidence: ssha vs. mss}

Vandemark et al. (2002) demonstrated that the on-orbit altimeter sea state bias can be estimated directly using altimeter sea surface height anomaly (ssha) data. These estimates are the deviation of instantaneous sea surface height measurements from the long-term averaged reference mean sea surface along the ground track. Here we use ssha as an indicator of the range bias to assess its linkage to sea surface roughness (i.e. $m s s$ ) estimates extracted from the differing WW3 wave model runs.

Fig. 4 (bottom panel) documents first evidence, indicating correlation between the surface wave mean square slope (mss) and the surface height anomaly (ssha) along a TOPEX ground 
track. With the increase in mss, the magnitude in ssha increases. Basically ssha is biased negative relative to the mean sea surface as anticipated.

Fig. 13a shows plots of the TOPEX-measured and significant wave height normalized range bias, the relative bias $\beta=s s h a / H_{\text {salt }}$, as a function of WW3 modeled mean square slope mss (both WW3-QN and WW3-NN mss shown) for the global datasets. Such plots depict a physical view of on-board altimeter relative range bias being linked to the wave model-derived surface wave steepness (i.e. mss). Both WW3-QN and WW3-NN mss show a high correspondence with the altimeter-observed relative range bias $\beta$. As expected from recent studies (e.g. Gommenginger et al., 2003), the relative bias magnitude increases with increase in the wave steepness mss. At $m s s^{\sim}=0.009$, the $\beta$ magnitude maximum of about $3 \%$ is reached under this global averaging. Beyond that, $\beta$ becomes flat and even recedes to $2.5 \%$.

Under closer inspection, the difference in bias behavior is observed between WW3-QN mss and WW3-NN mss results. For instance, for mss from 0.004 to 0.008 the increased rate in the bias $\beta$ with WW3-QN mss is steeper than with WW3-NN mss. This is the region with the highest data density. Fig. 13b provides the difference in the relative bias $\beta$ between the two, indicating the difference ranges between 0.2-0.5 percent of wave height for these differing model outputs. This level of discrepancy is significant in that the reason for using new wave model data in range bias correction work is to lower uncertainty that is presently of the order of $1 \%$ of $H_{s}$.

Range bias patterns similar to that shown in Fig. 13a have been reported in recent towerbased and aircraft-based in situ radar electromagnetic bias measurement studies (Millet et al., 2003; Melville at al., 2004; Vandemark et al., 2005). Particularly, they show that inclusion of slope variance or RMS slope in an electromagnetic model could improve the performance. In future work, multivariate statistical analysis will be applied to our collocated dataset of altimeter measurements and wave modeled parameters in efforts to extract additional model-based SSB information for a refinement of on-board altimeter range bias correction. The results of this study, including Fig. 13, warrant strong consideration of the wind forcing and resulting wave model output in these efforts.

\section{Discussion and Summary}

This study provides an evaluation of the global operational wave model (Wavewatch III) performance in terms of different wind forcing fields and using altimeter-based observations. The sensitivity of the WW3 model significant wave height $H_{s}$ to the wind forcing have been clearly documented in this study. The WW3-NN $H_{s}$ accords best with $H_{\text {salt }}$ at both global and regional scales although the NCEP/NCAR reanalysis winds are consistently biased negatively with respect to altimeter- or scatterometer-observed winds. The WW3 modeled $H_{s}$ by the other three winds (i.e. QN, EE, and ES) are all biased positively with the highest bias of the WW3-QN $H_{s}$. It is most likely because the present version of WW3 model was formed using winds similar to the NCEP/NCAR reanalysis winds used herein. In fact, the NCEP/NCAR wind forced model runs provide the best results in terms of $H_{s}$ estimates (Tolman, 2002). A consistent positive bias in the WW3-QN $H_{s}$ suggests that either 1) the NCEP/NCAR winds have a substantial negative bias or the Qscat/NCEP blended winds are biased positively or 2) the model implementation needs improvement. We have also shown that the positive bias in $H_{s}$ is mainly due to a positively biased swell component in the global view. From a close inspection by dividing the globe into regions, it has been noticed that excess swell energy generated at higher latitudes using the Qscat/NCEP blended winds is responsible for much of the disparities of the WW3 model at the lower latitudes. But at the same time the wave spectrum is slightly overdriven by the positively biased winds in our present WW3 configuration. This leads to substantial bias in the swell and lowest order wave 
moments. Our expectation is that the noted positive bias could be eliminated or at least diminished either by readjusting the wave model with the new forcing winds, or by assimilating the altimeter wave height into the wave model to acquire an optimal wave spectral estimate.

In this study, we are most interested in the wave model parameters $T_{z}$ and mss. These wave terms are related to the higher-order spectral moments, more closely associated with the local wind and wind sea. As expected, the WW3 modeled $T_{z}$ has less sensitivity to wind forcing changes, and WW3 modeled mss is most sensitive to wind forcing. On a global scale, we find that WW3modeled $T_{z}$ is biased high with respect to altimeter-derived $T_{\text {zalt }}$ while WW3-modeled mss accords somewhat more closely with altimeter-derived $m s s_{a l t}$. When viewed regionally, a more detailed picture emerges. For the high sea state cases (high latitudes), all wave parameters calculated for the model runs driven by four distinct forcing winds match each other fairly well, and also agree well with altimeter-derived parameters; although there exists some noticeable discrepancy at low wave height levels. These results suggest that WW3 output sensitivity to wind forcing is relatively less significant in such high sea state, high wind speed regions.

In the case of low sea state conditions, substantial discrepancies appear among the four WW3 model products. The most apparent difference is noticed between the WW3-NN and WW3-QN parameters $H_{s}$ and mss, but the difference appears quite small for $T_{z}$. This indicates that $H_{s}$ and $m s s$ are quite sensitive to wind forcing, while $T_{z}$ appears less so. This may be because $H_{s}$ and $m s s$ are directly proportional to the total spectral energy and the energy in the wave spectrum tail, respectively; while $T_{z}$ is proportional to the square root of the ratio of $m_{0}$ to $m_{2}$. Taking the ratio in calculating $T_{z}$ diminishes the effect of the positive bias in wave energy. Additionally, it should be noted that once compared with $T_{\text {zalt, }}$ the WW3 model $T_{z}$ is slightly overestimated in global comparisons and significantly so in the equatorial regions. It matches well in the high latitude region. These regional deviations in the WW3 model $T_{z}$ with respect to $T_{\text {zalt }}$ may be attributed to1) the uncertainty of the $T_{\text {zalt }}$ algorithm and 2 ) the varying positive bias effect in the wave energy due to wind forcing changes. The sensitivity of the WW3 model mss to wind forcing clearly shows that the WW3 modeled mean surface slope (mss) by using NN winds appears unreasonably low in comparison with the other three wind-driven WW3 model mss. The WW3-QN mss consistently gives the closest agreement with altimeter mss $_{a l t}$ at both global and regional scales.

This study is the first of its kind to evaluate the performance of the wave model estimates of $T_{z}$ and mss; parameters related to the wave spectrum's higher order moments in terms of altimeter- or altimeter-buoy-derived measurements. The altimeter-based assessment for wave model performance in this work is independent and well posed since the WW3 model wave parameters $\left(H_{s}, T_{z}\right.$ and $\mathrm{mss}$ ) are determined without any altimeter measurement assimilation. The altimeter wave parameters ( $T_{z}$ and $m s s$ ) are retrieved utilizing algorithms developed using NDBC buoy data as the ground truth. There is no doubt that these altimeter methods were not globally calibrated because NDBC buoys are not deployed globally, nor do they sample all differing wind and wave conditions. The regional deviations in the WW3 model $T_{z}$ and mss with respect to altimeter-derived values are certainly associated, in part, with uncertainties in these empirical altimeter algorithms for $T_{z}$ and $m s s$.

The agreement of the model-estimated $T_{z}$ and mss with altimeter-derived estimates at high latitudes suggests these algorithms were probably trained by the wave measurements at the NDBC buoys in these regions, and so the evaluation skill favors this region. In the equatorial regions, much worse performance of the WW3-modeled $T_{z}$ and mss with respect to altimeter estimates is documented, particularly for $T_{z}$. The WW3 model zero-crossing wave period $T_{z}$ shows that it seems to be difficult to model. This may be because $T_{z}$ is related to both the total wave energy and 
the energy at the intermediate scales and thus its accurate estimate requires a model wave spectrum with high quality over all the scales.

Overall, the best model performance in $H_{s}, T_{z}$, and mss is for the WW3 model outputs when forced by NN, ES or EE, and QN winds, respectively. This succinct summary regarding given statistics does not imply that any single run creates a more realistic complete directional spectrum than another. But it is clear that there are strong wave model response differences between runs forced by the NCEP/NCAR winds and wind fields that include satellite data enhancements. We conclude that the enhanced wind fields with higher spatial resolution, such as QuickSCAT/NCEP and ECMWF/SSMI products, are critical for driving the wave model such that variations in the higher-order moments $\left(m_{4}\right)$ can be picked up. These higher order moments actually contain rich information on the SSB of interest.

No altimeter observations were assimilated in the WW3 runs. One expects a performance improvement in future modeling once assimilation is implemented operationally. Many recent studies have shown that altimeter observation assimilation can improve wave height $H_{s}$ (Bidlot et al, 2002; Wittmann and Cummings,2004; Skandrani et al., 2004.) Therefore, the significant systematic positive bias we see in the WW3-QN $H_{s}$ could be corrected by altimeter assimilations. However, as suggested in our results regarding swell and higher-order moments, assimilation of only significant wave height $H_{s}$ might not be enough constraint to realize a realistic wave energy spectrum. A current study (Skandrani et al., 2004) shows no improvement in modeled wave period when assimilating altimeter wave height data into wave models. Their explanation is the fact that the current assimilation scheme only assimilates the wave height but not the wave period. Thus, it is expected that further improvements should come as assimilation methods make use of further wave spectral information, such as from satellite SAR spectral data or the higher-order altimeter parameters discussed in this study.

Finally, we have demonstrated a physical linkage between the altimeter-observed range bias and wave model derived high-order statistics, and as importantly, shown that the choice of wind forcing of the wave model will directly impact such relationships. Mean square slope mss estimated from an operational wave model may provide a candidate data set for inclusion in empirical attempts to derive an improved operational altimeter on-board range correction method and the present study suggests that such work will need to carefully consider the resolution and long-term stability of the wind model used in these efforts.

\section{Acknowledgements}

The authors wish to recognize the help of Paul Wittmann from the Fleet Numerical Meteorology and Oceanography Center during the Wavewatch III model implementation. The NCEP/NCAR reanalysis wind data were provided by the NOAA-CIRES Climate Diagnostics Center, Boulder, Colorado, USA (http://www.cdc.noaa.gov/). The QuickSCAT/NCEP blended wind data were obtained through the website at http://dss.ucar.edu/datasets/ds744.4/. The MSS/IECMWF wind data were provided by Joseph Ardizzone and Robert Atlas at the NASA Goddard Space Flight Center. The ice concentration data were obtained from the National Snow and Ice Data Center, Cooperative Institute for Research in Environmental Sciences (CIRES), Coulder, CO, USA. The research reported here was sponsored by NASA's Science Directorate. Hui Feng also acknowledges financial support from GEST/NASA-GSFC. 


\section{References}

Atlas, R., Hoffman, R., Bloom, S., Jusem, J., Ardizzone, J., 1996. A multi-year global surface wind velocity data set using SSM/I wind observations. Bulletin of the American Meteorological Society, 77, 5, 869-882.

Abdalla, S., Cavaleri, L., 2002. Effect of wind variability and variable air density on wave modeling. Journal of Geophysical Research, 107, C7, 17-1-20.

Bauer, E., Weisse, R., 2000. Determination of high-frequency wind variability from observations and application to North Atlantic wave modeling. Journal of Geophysical Research, 105, C11, 26179-26190.

Bidlot, J.R., Holmes, D.J., Wittmann, A.P., Lalbeharry, R., Chen, H.S., 2002. Intercomparison of the performance of operational ocean wave forecasting systems with buoy data. Weather and Forecasting, 17, 287-310.

Cavaleri, L. et al., 1994. Applications to wave hindcasting and forecasting (Chapter IV), In Dynamics and Modeling of Ocean Waves, Cambridge University Press, USA (pp.532).

Cavalieri, D. J., Gloersen, P., and Campbell, W.J., 1984. Determination of sea ice parameters with the NIMBUS-7 SMMR. Journal of Geophysical Research, 89, D4, 5355-5369.

Chapron, B., Vandemark, D., Elfouhaily,T., Thompson, D.R., Gaspar, P., LaBroue, S., 2001. Altimeter sea state bias: a new look at global range error estimates. Journal of Geophysical Research, 28, 20, 3947-3950.

Chin, T.M., Milliff, R.F., Large, W.G., 1998. Basin-scale, high-wavenumber sea surface wind fields from a multiresolution analysis of scatterometer data. Journal of atmospheric and oceanic technology, 15, 741-763.

Elfouhaily, T., Thompson, D., Chapron, B.,Vandemark, D., 1999. Weakly nonlinear theory and sea state bias theory. Journal of Geophysical Research, 140, C4, 7641-7647.

Elfouhaily, T., Thompson, D., Chapron, B.,Vandemark, D.,2000. Improved electromagnetic bias theory. Journal of Geophysical Research, 105, C1, 1299-1310.

Gaspar, P., Labroue, S., Ogor, F., Lafitte, G., Marchal, L., Rafanel, M., 2002. Improving nonparametric estimates of the sea state bias in radar altimeter measurements of sea level. Journal of atmospheric and oceanic technology, 19,1690-1707.

Gommenginger, C. P., Srokosz, M. A., Wolf, J., Janssen, P. A. E. M., 2003. An investigation of altimeter sea state bias theories. Journal of Geophysical Research, 108,C1, 3011.

Gourrion, J., Vandemark, D., Bailey, S. A., Chapron, B., Gommenginger, C., Challenor, P., Srokosz, M. A., 2002a. A two parameter wind speed algorithm for Ku-band altimeters. Journal of atmospheric and oceanic technology, 19, 12, 2030-2048.

Gourrion, J., Vandemark, D., Bailey, S. A., Chapron, B., 2002b. Investigation of C-band altimeter cross section dependence on wind speed and sea state. Canadian Journal of Remote Sensing, 28, 3, 484-489.

Hanson, J. L., Phillips, O.M., 2001. Automated analysis of ocean surface directional wave spectra. Journal of atmospheric and oceanic technology, 18, 277-293.

Isaksen, L., Janssen, P.E.M., 2004. Impact of ERS scatterometer winds in ECMWF's assimilation system. Quarterly Journal of the Royal Meteorological Society, 130, Part B, 603, 1793-1814.

Kalnay, E., Kanamitsu, M., Kistler, R., Collins,W., Deaven, D., Gandin,L., Iredell,M., Saha, S., White,G., Woollen, J., Zhu, Y., Chelliah,M., Ebisuzaki, W., Higgins,W., Janowiak,J., Mo,K.C., Ropelewski, C., Leetmaa, A., Reynolds,R., and Jenne, R., 1996. The NCEP/NCAR 40-year reanalysis project. Bulletin of the American Meteorological Society, 77, 437-471. 
Kistler R., and Coauthors, 2001. The NCEP-NCAR 50-Year Reanalysis: Monthly Means CDROM and Documentation. Bulletin of the American Meteorological Society, 82, 24, 2001.7267.

Koblinsky, C.J., Beckley, B.D., Ray, R.D., Wang, Y.-M., Brenner, A., 1998. NASA Ocean altimeter pathfinder project report No. 1: Data Processing Handbook, Goddard Technical Memorandum.

Komen, G.L., Cavaleri, L., Domelan, M., Hasselmann, K., Hasselmann, S., and Janssen, P.A.E., 1994. Dynamics and Modeling of Ocean Waves, Cambridge University Press (pp. 532).

Kumar, R., Stammer, D., Melville, W. K., Janssen, P.A.E., 2003. Electromagnetic bias estimates based on TOPEX, buoy, and wave model data. Journal of Geophysical Research, 108, C11, 3351.

Melville, K.W., Felizardo, F.C., Matusov, P., 2004. Wave slope and wave age effects in measurements of electromagnetic bias. Journal of Geophysical Research, 109, C0,7018.

Millet, F., Arnold, D.V., Warnick, K. F., Smith, J., 2003a. Electromagnetic bias estimation using in situ and satellite data: 1. RMS wave slope. Journal of Geophysical Research, 108, C2, 3040.

Millet, F., Arnold, D.V., Gaspar, P., Warnick, K. F., Smith, J., 2003b. Electromagnetic bias estimation using in situ and satellite data: 2. A nonparametric approach. Journal of Geophysical Research, 108, C2, 3041.

Milliff, R.F., Large, W.G., Morzel, J., Danabasoglu, G., Chin, T.M., 1999. Ocean general circulation model sensitivity to forcing from scatterometer winds. Journal of Geophysical Research, C5, 11337-11358.

Milliff, R.F., Morzel, J., Dudley, B., Freilic, M., 2004. Wind stress curl and wind stress divergence biases from rain effects on QSCAT surface wind retrievals. Journal of atmospheric and oceanic technology, 21, 1216-1231.

Moon, I.-J., Ginis,I., Hara, T., Tolman,H., Wright, C.W. and Walsh, E.J., 2003. Numerical Simulation of Sea-surface Directional Wave Spectra under Hurricane Wind Forcing , Journal of Physical Oceanography, 33.,1680-1706.

Ponce, S., Ocampo-Torres, F.J., 1998. Sensitivity of a wave model to wind variability. Journal of Geophysical Research, 103, C2, 3179-3202.

Quilfen, Y., Chapron, B., Collard, F., Serre, M., 2004. Calibration/validation of an altimeter wave period model and application of Topex/Poseidon and Janso-1 altimeters. Marine Geodesy (Special Issue on Jason1 Calibration/Validation III), 27,535-549.

Rabier, F., Jarvinen, H., Klinker, E., Mahfouf, J.F., Simmons, A., 2000. The ECMWF operational implementation of four-dimensional variational assimilation. I: Experimental results with simplified physics. Quarterly Journal of the Royal Meteorological Society, 126, 564, 1143.

Rogers, W.E. and Wittmann, P.A., 2002. Quantifying the role of wind field accuracy in the U.S. Navy's global ocean wave nowcast/forecast system, NRL Memorandum Report.

Skandrani, C., Lefevre, J.M., and Queffeulou, P., 2004. Impact of Multisatellite altimeter data assimilation on wave analysis and forecast, 27, Marine Geodesy (Special Issue on Jason1 Calibration / Validation III), 511,-533.

Tolman, H. L., and Chalikov, D. V., 1996. Source terms in a third-generation wind-wave model. Journal of Physical Oceanography, 26, 2497-2518.

Tolman, H. L., 2002. Validation of WAVEWATCH III version 1.15 for a global domain. NOAA / NWS / NCEP / OMB Technical Note Nr. 213, 33 pp.

Tolman, H. L., Balasubramaniyan,B., Burroughs, L. D. , Chalikov, D. V., Chao, Y. Y., Chen, H. S. and Gerald, V. M. , 2002. Development and implementation of wind generated ocean surface wave models at NCEP. Weather and Forecasting, 17, 311-333. 
Vandemark, D., Tran, N., Beckley, B. D., Chapron, B., Gaspar, P., 2002. Direct estimation of sea state impacts on radar altimeter sea level measurements. Geophysical Research Letters,. 29 (24), 2148.

Vandemark, D., Chapron, B., Elfouhaily, T., Drennan, W., Campbell, J.W., 2005. Impact of high frequency waves on the ocean altimeter range bias, 2005. Journal of Geophysical Research, submitted.

WAMDI Group, 1988. The WAM model - a third generation wind wave model. Journal of Physical Oceanography, 18, 1775-1810.

Wittmann, P.A., and Cummings, J.A., 2004. Assimilation of altimeter wave measurements into Wavewatch III. The 8th International Workshop on Wave Hindcasting \& Forecasting, North Shore, Oahu, Hawaii, November 14-19. 
Table 1. The characteristics of the four wind forcing fields used in this study

\begin{tabular}{|c|c|c|c|c|}
\hline & $\begin{array}{c}\text { NCEP/NCAR } \\
\text { Reanalysis } \\
(\mathrm{NN})\end{array}$ & $\begin{array}{c}\text { QSCAT/NCEP } \\
\text { Blended } \\
(\mathrm{QN})\end{array}$ & $\begin{array}{c}\text { ECMWF } \\
\text { ERS1,2 assimilated } \\
(\mathrm{EE})\end{array}$ & $\begin{array}{c}\text { ECMWF } \\
\text { SSM/I assimilated } \\
(\mathrm{ES})\end{array}$ \\
\hline $\begin{array}{c}\text { Spatial } \\
\text { resolution }\end{array}$ & $1.875^{\circ}$ by $1.900^{\circ}$ & $0.5^{\circ}$ by $0.5^{\circ}$ & $1.125^{\circ}$ by $1.125^{\circ}$ & $1.0^{\circ}$ by $1.0^{\circ}$ \\
\hline $\begin{array}{c}\text { Temporal } \\
\text { resolution }\end{array}$ & 6 hour & 6 hour & 6 hour & 6 hour \\
\hline $\begin{array}{c}\text { Mapping } \\
\text { algorithm }\end{array}$ & $\begin{array}{c}\text { NCEP } \\
\text { atmospheric } \\
\text { model }\end{array}$ & DIRTH & 4-D VAR & 2-D VAM \\
\hline Reference & $\begin{array}{c}\text { Kalnay et al, } \\
1996 \text { Kistler et } \\
\text { al. 2001 }\end{array}$ & $\begin{array}{c}\text { Chin et al., 1996 } \\
\text { Milliff et al., } \\
1999\end{array}$ & Rabier et al., 2000 & Atlas et al., 1996 \\
\hline
\end{tabular}

Table 2. List of the collocated TOPEX-derived and WW3-modeled parameters

\begin{tabular}{|c|c|}
\hline \multicolumn{2}{|c|}{ TOPEX-derived variables } \\
\hline ssha & sea surface height anomaly \\
\hline$H_{\text {salt }}$ & significant wave height \\
\hline$U_{10 a l t}$ & wind speed at $10 \mathrm{~m}$ \\
\hline$T_{\text {zalt }}$ & mean zero crossing wave period (Eq. 2) \\
\hline$m s S_{\text {alt }}$ & mean square slope (Eq. 1) \\
\hline$\sigma_{k u}$ and $\sigma_{c}$ & $\mathrm{Ku}-$ and C-band radar cross sections \\
\hline \multicolumn{2}{|c|}{$\begin{array}{l}\text { Winds and WW3 model parameters } \\
\text { (with four products associated with four different winds) }\end{array}$} \\
\hline$U_{10}$ & wind speed at $10 \mathrm{~m}$ \\
\hline$H_{S}$ & WW3-modeled significant wave heights \\
\hline $\begin{array}{l}s H_{s} \\
w H_{s}\end{array}$ & $\begin{array}{l}\text { WW3-modeled swell significant heights } \\
\text { WW3-modeled wind sea significant heights }\end{array}$ \\
\hline$T_{Z}$ & WW3-modeled mean zero crossing wave period \\
\hline mss & WW3-modeled mean square slope \\
\hline $\begin{array}{r}\text { Note WW3-modeled p } \\
\text { - } \text { The ith order m } \\
\text { - } \text { Significant wav } \\
\text { - Zero-crossing } \\
\text { - Mean square sl }\end{array}$ & $\begin{array}{l}\text { rs are calculated from the following definitions } \\
\qquad m_{i}=\iint E(f, \theta) f^{i} d f d \theta \\
\text { t: } H_{s}=4 \sqrt{m_{0}} \\
\text { riod: } \quad T_{z}=\sqrt{m_{0} / m_{2}} \\
\quad m s s=(2 \pi)^{4} g^{-4} m_{4}\end{array}$ \\
\hline
\end{tabular}


Table 3 Selected regions with their geographical extents

\begin{tabular}{|c|c|c|}
\hline Regions & Longitude range & Latitude range \\
\hline Global & $0-360$ & $-66 \mathrm{~S}-66 \mathrm{~N}$ \\
\hline Northern Ocean (N.O.) & $0-360$ & $47 \mathrm{~N}-66 \mathrm{~N}$ \\
\hline Southern Ocean (S.O.) & $0-360$ & $66 \mathrm{~S}-47 \mathrm{~S}$ \\
\hline Equatorial Pacific (E.P.) & $173-246$ & $20 \mathrm{~S}-20 \mathrm{~N}$ \\
\hline Eastern Equatorial Pacific (E.E.P.) & $250-268$ & $0-20 \mathrm{~N}$ \\
\hline
\end{tabular}


Table 4. Error analysis statistics for comparisons of WW3-modeled parameters versus TOPEXobserved. Bias, RMSE, SI and $r$ indicate mean error, root mean square error, scatter index and correlation coefficient, respectively, in terms of the WW3-modeled parameter against the TOPEX-observed ones. Mean and standard values for each parameter are also given. The numbers bolded indicate the best performance in the very measure among the four products.

\begin{tabular}{|c|c|c|c|c|c|c|c|}
\hline & & Bias & RMSE & $S I$ & $r$ & Mean & std \\
\hline GLOE & BAL - . - & --- & & -- & 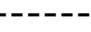 & $\cdots$ & 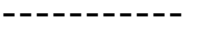 \\
\hline U10 & TOPEX & & & & & 7.76 & 3.83 \\
\hline & WW3-QN & 0.25 & 1.75 & 0.23 & 0.89 & 8.01 & 3.67 \\
\hline & WW3-NN & -0.31 & 2.61 & 0.34 & $\odot .75$ & 7.46 & 3.49 \\
\hline & WW3-EE & -0.32 & 1.91 & 0.25 & 0.87 & 7.44 & 3.49 \\
\hline & WW3-ES & -0.08 & 1.62 & 0.21 & 0.91 & 7.69 & 3.43 \\
\hline$H S$ & TOPEX & & & & & 2.69 & 1.40 \\
\hline & WW3-QN & 0.49 & $\odot .70$ & 0.26 & 0.94 & 3.18 & 1.47 \\
\hline & WW3-NN & 0.04 & 0.60 & 0.22 & 0.91 & 2.73 & 1.37 \\
\hline & WW3-EE & -0.00 & 0.50 & 0.19 & 0.94 & 2.69 & 1.37 \\
\hline & WW3-ES & $\odot .12$ & 0.52 & $\odot .19$ & 0.93 & 2.81 & 1.30 \\
\hline$T z$ & TOPEX & & & & & 6.81 & 1.43 \\
\hline & WW3-QN & $\odot .71$ & 1.23 & 0.18 & 0.72 & 7.51 & 1.23 \\
\hline & WW3 - NN & 0.38 & 1.17 & 0.17 & 0.66 & 7.18 & 1.23 \\
\hline & WW3-EE & 0.33 & 1.12 & $\odot .16$ & 0.67 & 7.14 & 1.23 \\
\hline & WW3-ES & 0.37 & 1.11 & 0.16 & 0.69 & 7.18 & 1.15 \\
\hline mss & TOPEX & & & & & $7.24 \mathrm{E}-3$ & $4.19 \mathrm{E}-3$ \\
\hline & WW3-QN & $-0.05 E-3$ & $1.78 \mathrm{E}-3$ & 0.25 & 0.91 & $7.19 \mathrm{E}-3$ & $3.87 \mathrm{E}-3$ \\
\hline & WW3-NN & $-\odot .89 E-3$ & $2.24 \mathrm{E}-3$ & 0.31 & 0.87 & $6.35 \mathrm{E}-3$ & $3.94 \mathrm{E}-3$ \\
\hline & WW3-EE & $-0.96 E-3$ & $2.02 \mathrm{E}-3$ & 0.28 & 0.90 & $6.28 \mathrm{E}-3$ & $3.93 \mathrm{E}-3$ \\
\hline & WW3-ES & $-0.58 E-3$ & $1.88 \mathrm{E}-3$ & $\odot .26$ & $\odot .9 \odot$ & $6.67 \mathrm{E}-3$ & $3.76 \mathrm{E}-3$ \\
\hline Nort & thern oc & ।- - - - - & 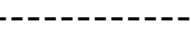 & -1 & - - - - - & - - - - - - - - & - - - - - - - \\
\hline U10 & TOPEX & & & & & 8.90 & 4.45 \\
\hline & WW3 - QN & -0.01 & 1.93 & 0.22 & 0.91 & 8.89 & 4.41 \\
\hline & WW3 - NN & -0.38 & 3.11 & 0.35 & 0.75 & 8.52 & 4.14 \\
\hline & WW3-EE & -0.71 & 2.54 & 0.29 & 0.84 & 8.20 & 3.96 \\
\hline & WW3-ES & -0.53 & 1.81 & 0.20 & 0.92 & 8.38 & 4.05 \\
\hline Hs & TOPEX & & & & & 2.94 & 1.76 \\
\hline & WW3-QN & $\odot .25$ & 0.67 & 0.23 & 0.94 & 3.19 & 1.85 \\
\hline & WW3-NN & -0.04 & 0.75 & 0.26 & 0.91 & 2.91 & 1.71 \\
\hline & WW3-EE & $-\odot .24$ & 0.75 & $\odot .25$ & 0.92 & 2.71 & 1.54 \\
\hline & WW3-ES & -0.13 & 0.65 & 0.22 & 0.93 & 2.81 & 1.66 \\
\hline$T z$ & TOPEX & & & & & 6.72 & 1.61 \\
\hline & WW3-QN & $\odot .22$ & 1.03 & 0.15 & 0.78 & 6.94 & 1.32 \\
\hline & WW3 - NN & -0.03 & 1.06 & 0.16 & 0.75 & 6.69 & 1.29 \\
\hline & WW3-EE & -0.16 & 1.07 & 0.16 & 0.76 & 6.56 & 1.20 \\
\hline & WW3-ES & -0.05 & 1.07 & 0.16 & 0.75 & 6.67 & 1.25 \\
\hline mss & TOPEX & & & & & $8.29 \mathrm{E}-3$ & $4.86 E-3$ \\
\hline & WW3 - QN & $-0.01 \mathrm{E}-3$ & $2.03 E-3$ & 0.25 & 0.91 & $8.15 E-3$ & $4.32 \mathrm{E}-3$ \\
\hline & WW3 - NN & $-\odot .06 E-3$ & $2.39 E-3$ & 0.29 & 0.88 & $7.70 \mathrm{E}-3$ & $4.29 E-3$ \\
\hline & WW3-EE & $-0.10 E-3$ & $2.55 \mathrm{E}-3$ & 0.31 & 0.88 & $7.26 \mathrm{E}-3$ & $4.10 \mathrm{E}-3$ \\
\hline & WW3-ES & $-\odot .09 E-3$ & $2.15 \mathrm{E}-3$ & $\odot .26$ & 0.92 & $7.41 \mathrm{E}-3$ & $4.19 \mathrm{E}-3$ \\
\hline East & tern Equ & orial Pac & - - - - - - - & -- & $\cdots$ & - - - - - - - - & - - - - - - - \\
\hline U10 & TOPEX & & & & & 4.85 & 2.66 \\
\hline & WW3-QN & 0.45 & 1.68 & $\odot .35$ & $\odot .80$ & 5.30 & 2.37 \\
\hline & WW3-NN & $-\odot .65$ & 2.59 & $\odot .53$ & 0.46 & 4.21 & 2.05 \\
\hline & WW3-EE & 0.01 & 1.91 & $\odot .39$ & 0.71 & 4.87 & 2.14 \\
\hline & WW3-ES & 0.48 & 1.62 & 0.34 & 0.82 & 5.33 & 2.33 \\
\hline$H S$ & TOPEX & & & & & 1.79 & 0.44 \\
\hline & WW3 - QN & 0.45 & 0.54 & 0.30 & 0.79 & 2.24 & 0.48 \\
\hline & WW3 - NN & -0.05 & 0.34 & 0.19 & 0.68 & 1.75 & 0.39 \\
\hline & WW3-EE & 0.03 & 0.29 & 0.16 & $\odot .77$ & 1.82 & 0.41 \\
\hline & WW3-ES & 0.11 & 0.31 & 0.17 & 0.78 & 1.90 & 0.45 \\
\hline$T z$ & TOPEX & & & & & 6.60 & 1.08 \\
\hline & WW3-QN & 1.62 & 1.98 & $\odot .30$ & 0.64 & 8.22 & 1.47 \\
\hline & WW3 - NN & 1.76 & 2.28 & 0.35 & 0.49 & 8.36 & 1.63 \\
\hline & WW3-EE & 1.42 & 1.93 & $\odot .29$ & 0.58 & 8.02 & 1.59 \\
\hline & WW3-ES & 1.13 & 1.65 & 0.25 & 0.64 & 7.73 & 1.53 \\
\hline mss & TOPEX & & & & & $3.85 \mathrm{E}-3$ & $2.02 \mathrm{E}-3$ \\
\hline & WW3-QN & $-0.27 E-3$ & 1. $37 \mathrm{E}-3$ & 0.36 & 0.81 & $3.58 \mathrm{E}-3$ & $2.26 \mathrm{E}-3$ \\
\hline & WW3-NN & $-1.77 \mathrm{E}-3$ & $2.61 \mathrm{E}-3$ & 0.68 & 0.53 & $2.08 \mathrm{E}-3$ & $1.92 \mathrm{E}-3$ \\
\hline & WW3-EE & $-1.15 E-3$ & 1.91E-3 & 0.50 & 0.72 & $2.70 \mathrm{E}-3$ & $2.06 \mathrm{E}-3$ \\
\hline & WW3-ES & $-0.53 E-3$ & $1.47 \mathrm{E}-3$ & 0.38 & 0.81 & $3.32 \mathrm{E}-3$ & $2.36 \mathrm{E}-3$ \\
\hline
\end{tabular}


a) mean $\mathrm{U} 10$ (QN) in Jan/2000

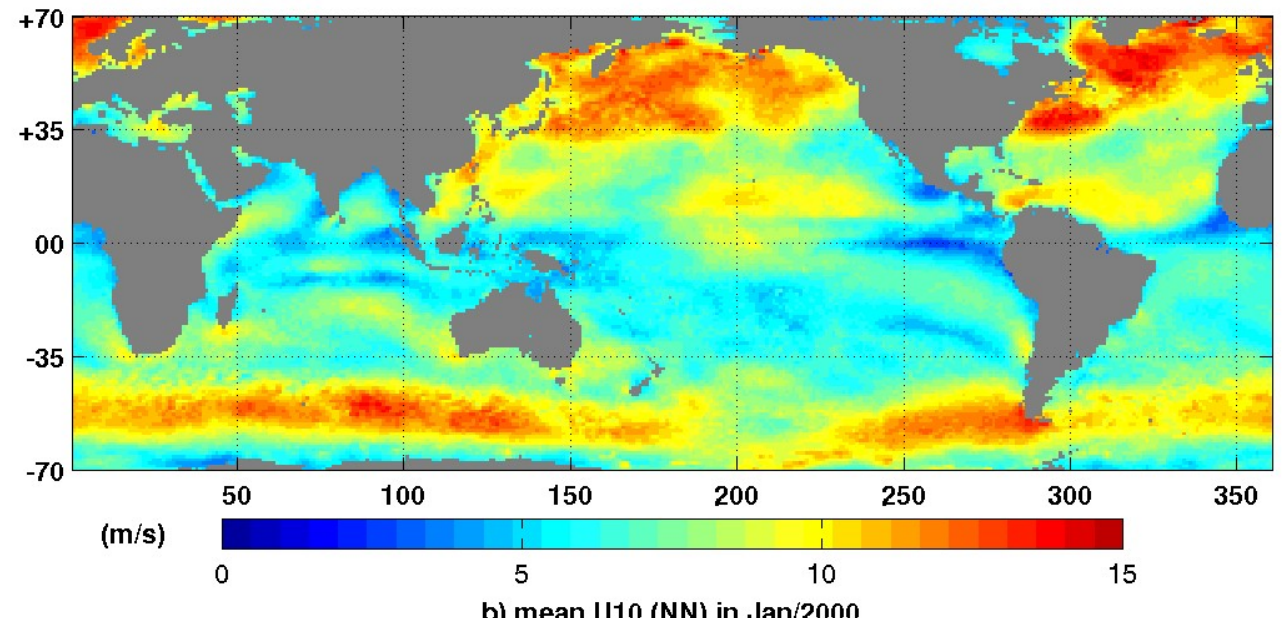

b) mean $\mathrm{U} 10$ (NN) in Jan/2000

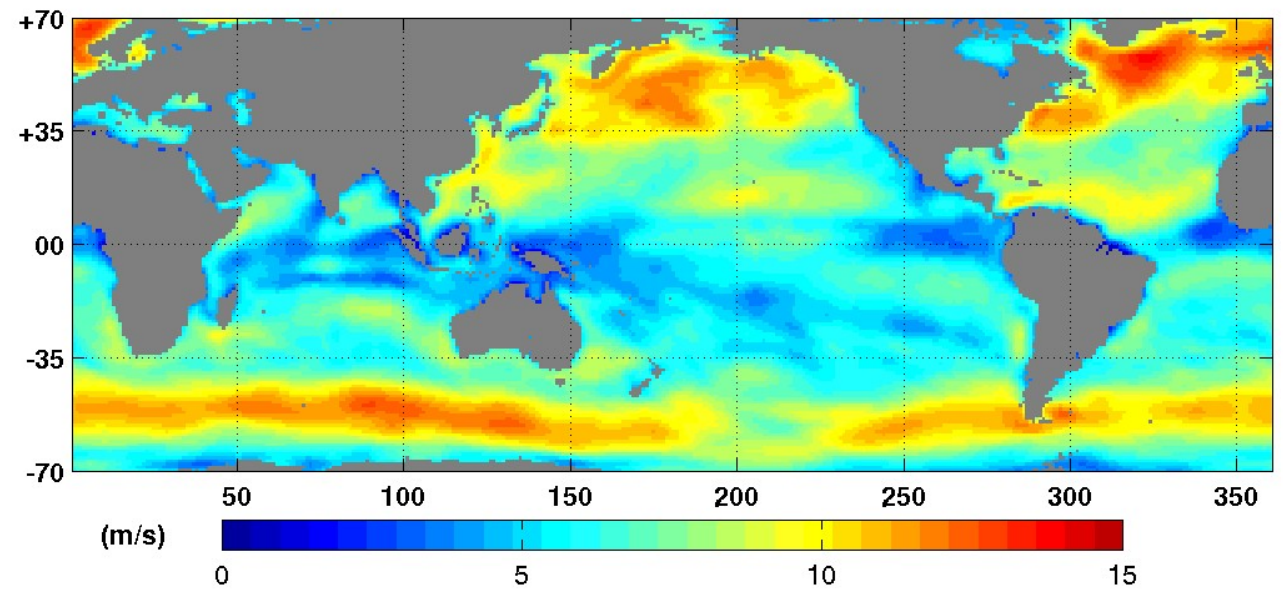

c) differnce in mean U10 (QN-NN) in Jan/2000

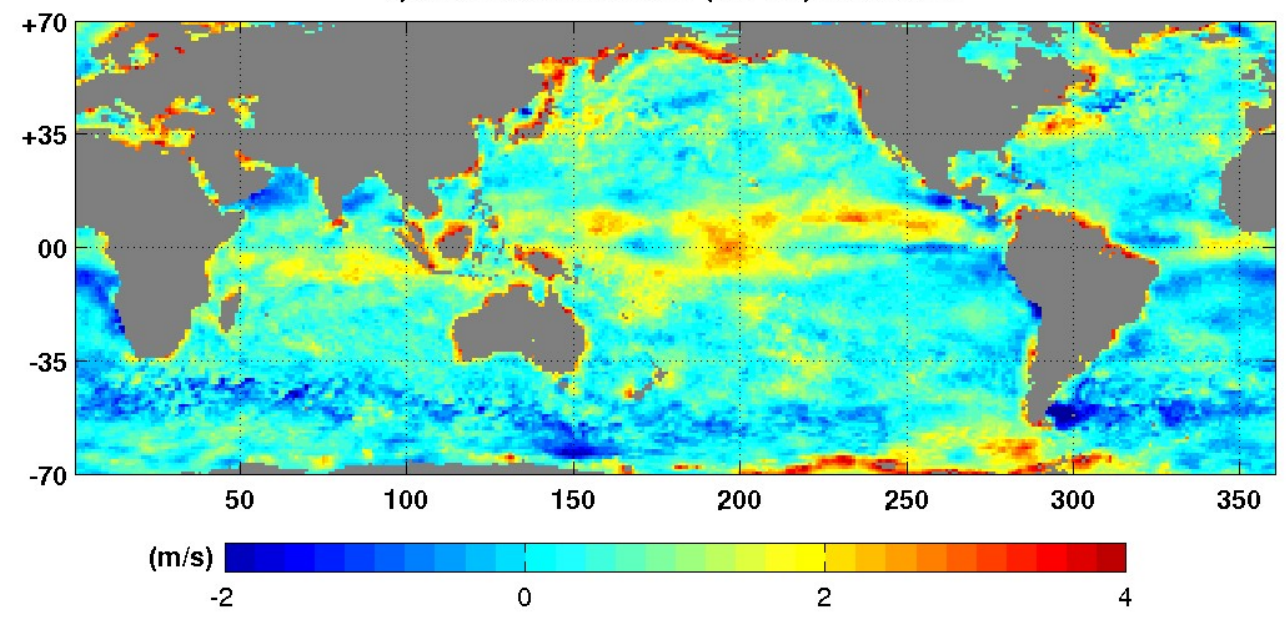

Fig. 1. Global mean wind speed $U_{10}$ maps for the month of January, 2000. (a) QuickScat/NCEP (QN); (b) NCEP/NCAR (NN); and (c) mean difference map of wind speed $U_{10}(\mathrm{QN}$ minus NN). 
a) difference in mean $\mathrm{H}_{\mathrm{s}}(\mathrm{QN}-\mathrm{NN})$ in Jan/2000
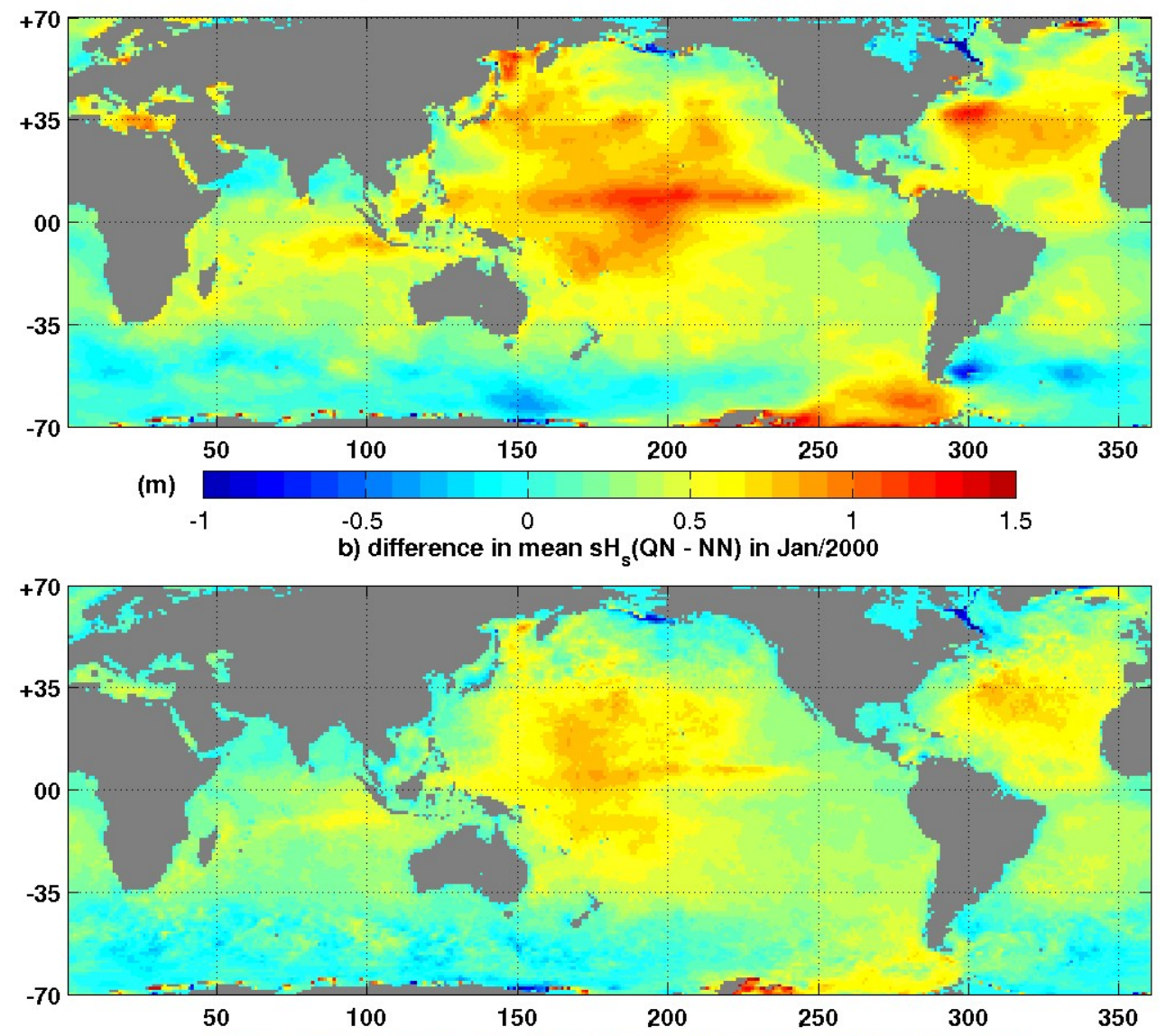

(m)

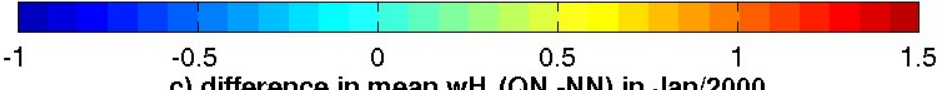

c) difference in mean $\mathrm{wH}_{\mathrm{s}}(\mathrm{QN}-\mathrm{NN})$ in Jan/2000

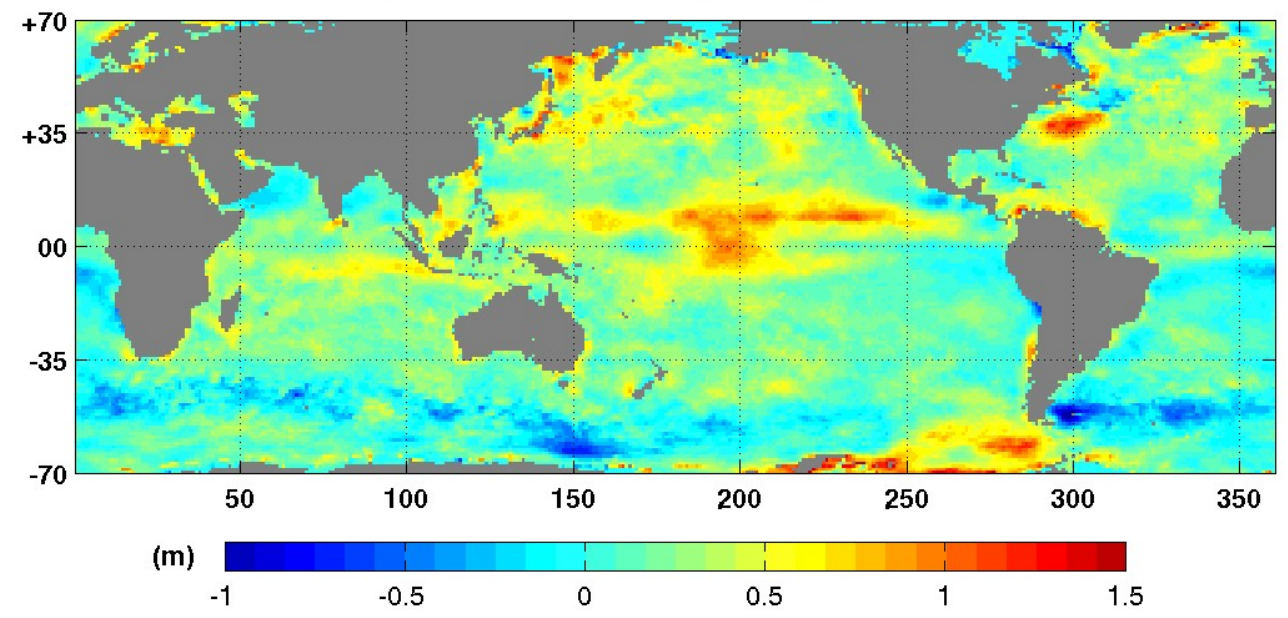

Fig. 2. Global mean difference maps of the WW3 model wave height components for the month of January of 2000. (a) significant wave height $H_{s}$; (b) swell height $s H_{s}$; and (c) windsea height $w H_{s}$ ( WW3-QN minus WW3-NN). 
a) mean mss (QN) in Jan/2000
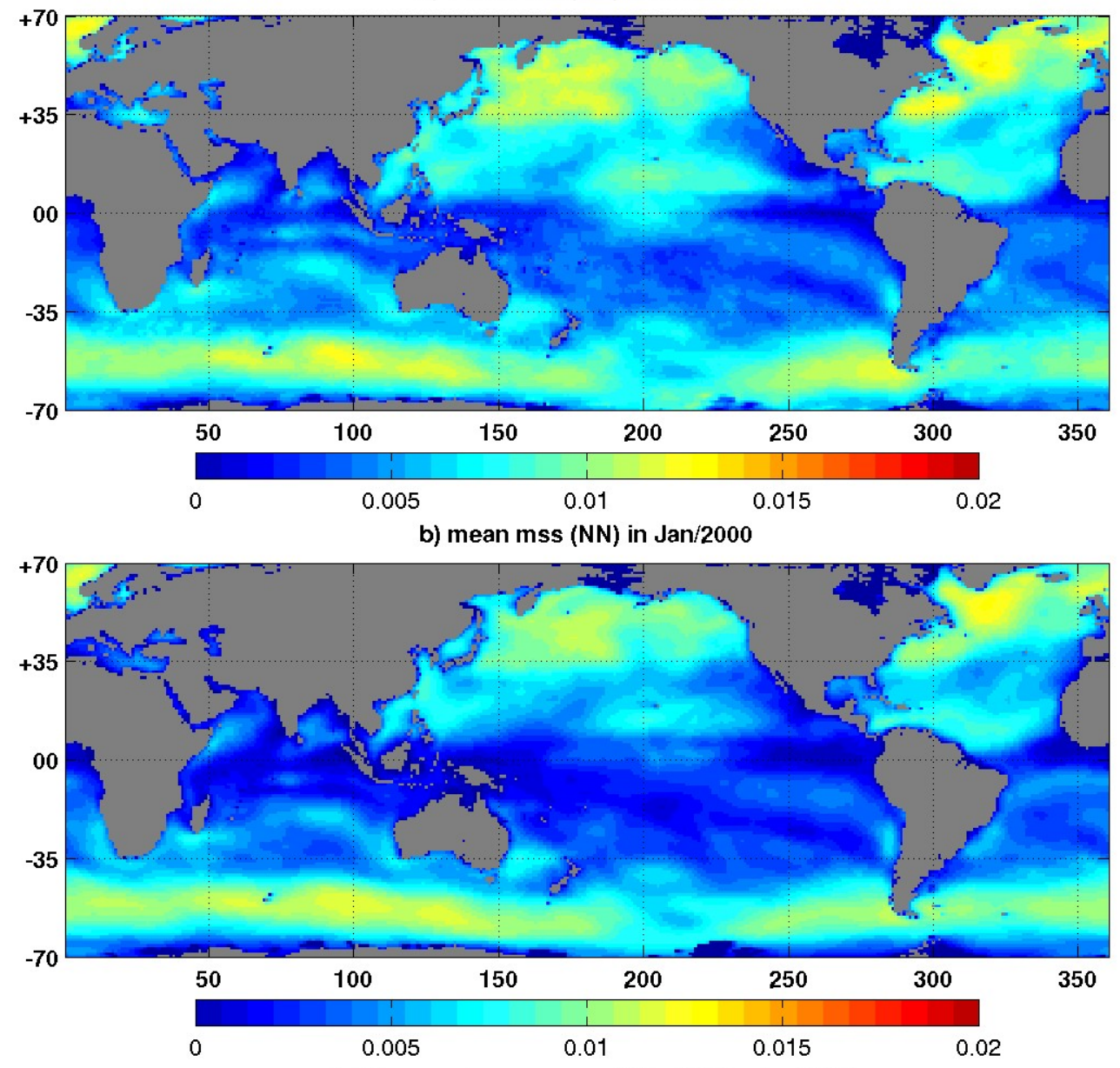

c) difference in mean mss (QN - NN) in Jan/2000

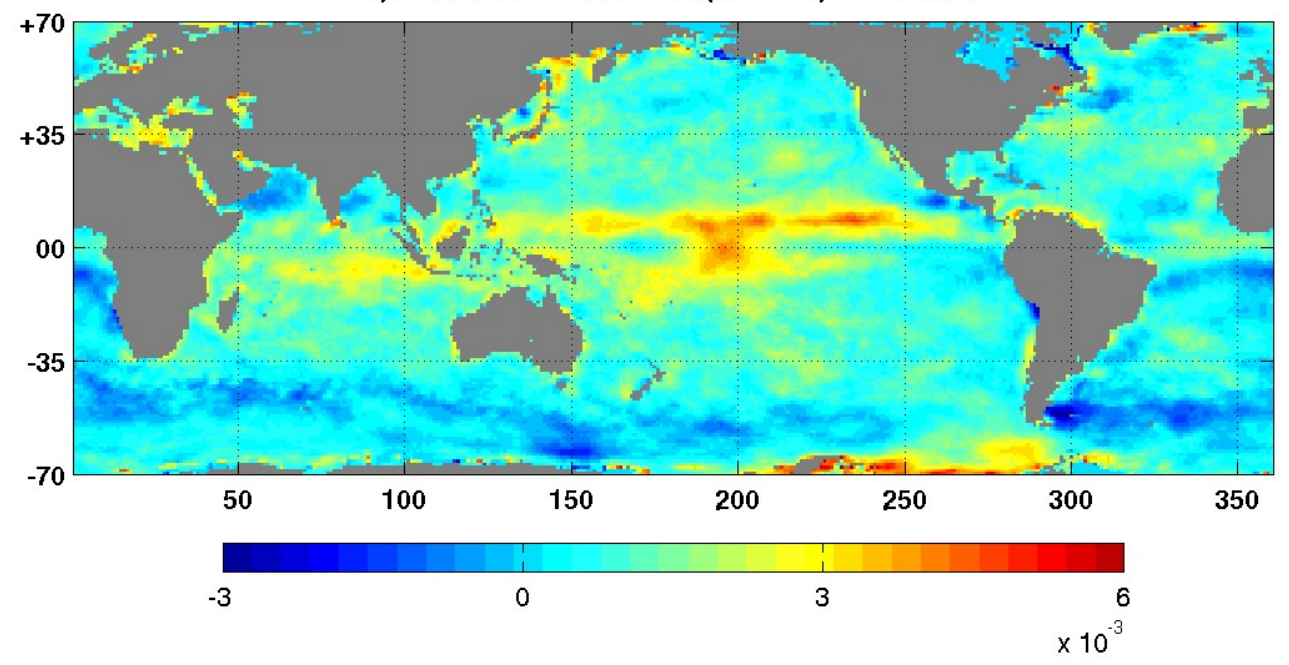

Fig. 3. Global mean maps of the WW3 model mean square slope mss for the month of Janary, 2000. (a) WW3-QN mss; (b) WW3-NN mss; and (c) The difference map of the WW3 model mss (WW3-QN minus WW3-NN). 

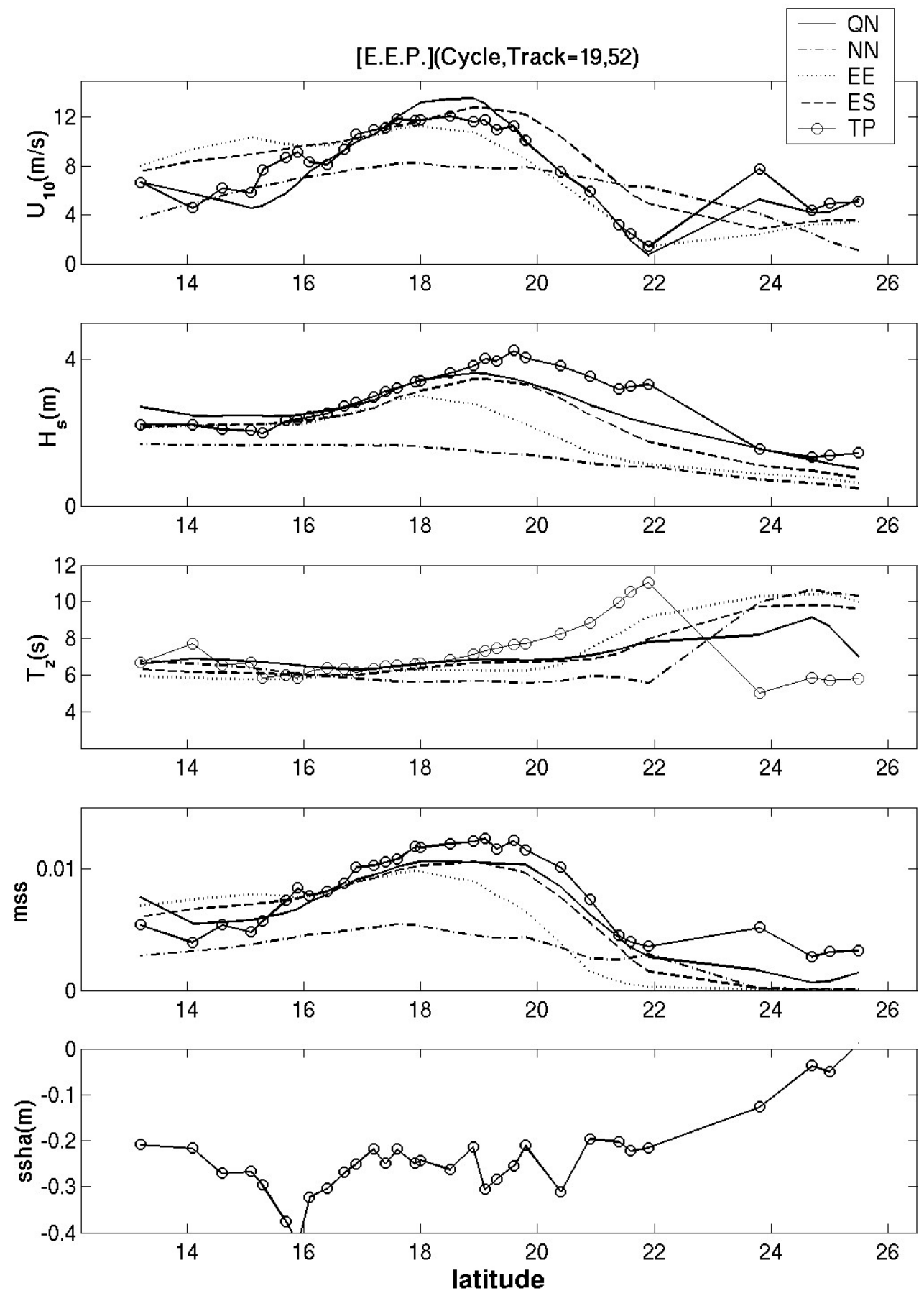

Fig. 4. A point-to-point comparison of WW3 modeled ( by QN, NN,EE, and ES winds) and TOPEX altimeter-derived wave parameters along an approximate $1500 \mathrm{~km}$ ground track in the Eastern Equatorial Pacific region. The panels from top to bottom represent wind speed $\left(U_{10}\right)$, significant wave height $\left(H_{s}\right)$, mean zero-crossing wave period $\left(T_{z}\right)$, surface mean square slope ( $\left.m s s\right)$, and the sea surface height anomaly (ssha), respectively. 

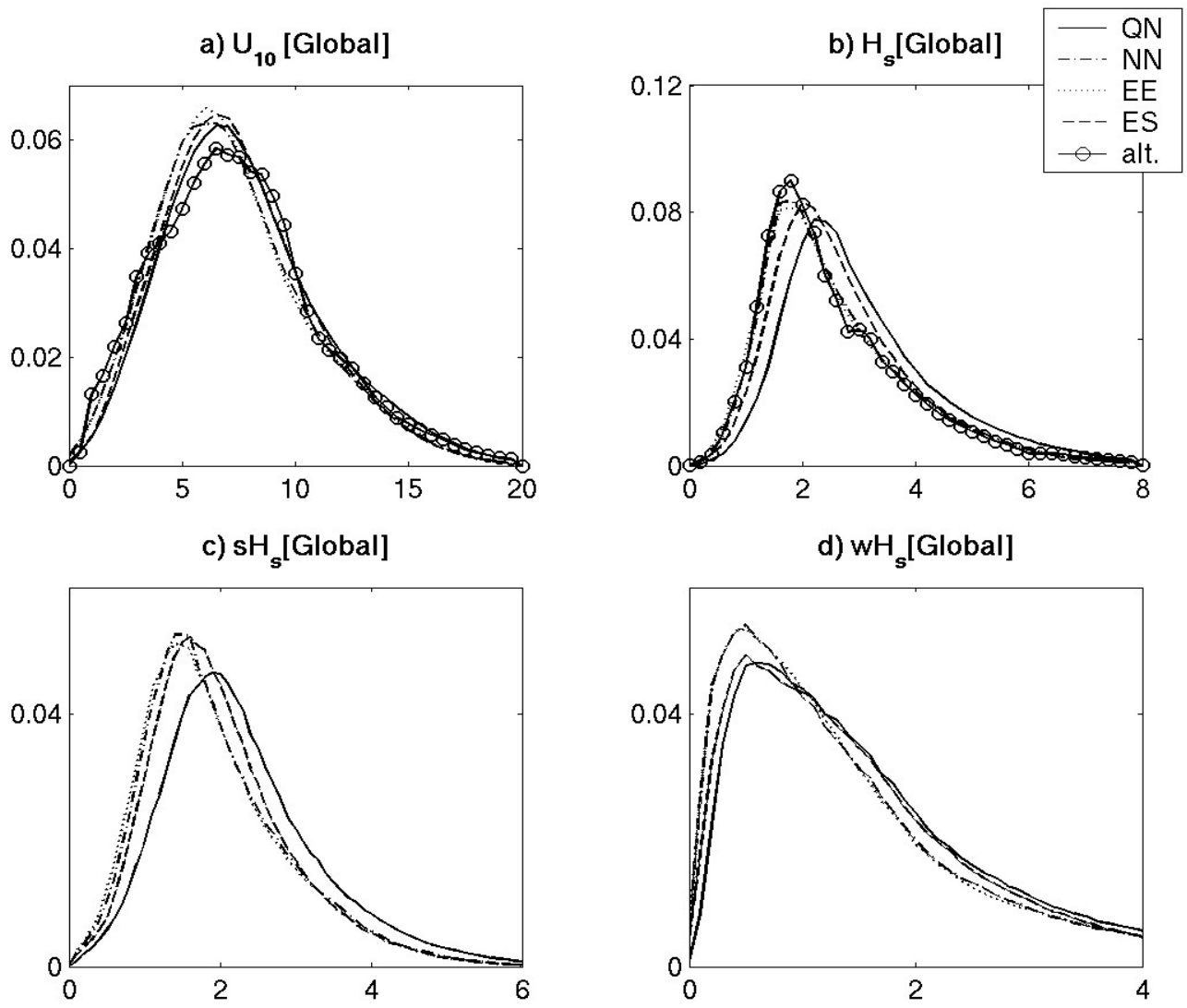

e) $\mathrm{T}_{z}$ [Global]
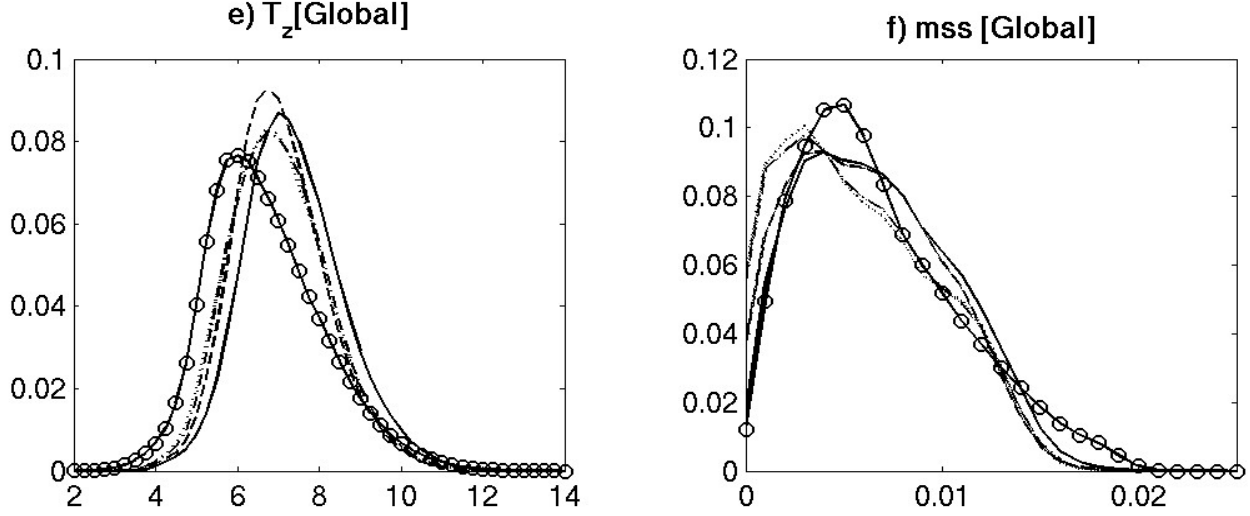

Fig.5 Validation and comparison of the distributions for six wind wave parameters (Global). The WW3 products are generated using four different wind fields as noted in the text. Altimeter estimates are also provided as indicated. (a) wind speed $U_{10}$; (b) wave height $H_{s}$; (c) swell wave height $s H_{s}$; (d) windsea height $w H_{s}$; (e) zerocrossing wave period $T_{z}$; and (f) mean square slope mss. Note that neither $s H_{s}$ nor $w H_{s}$ has an estimate from the altimeter. 

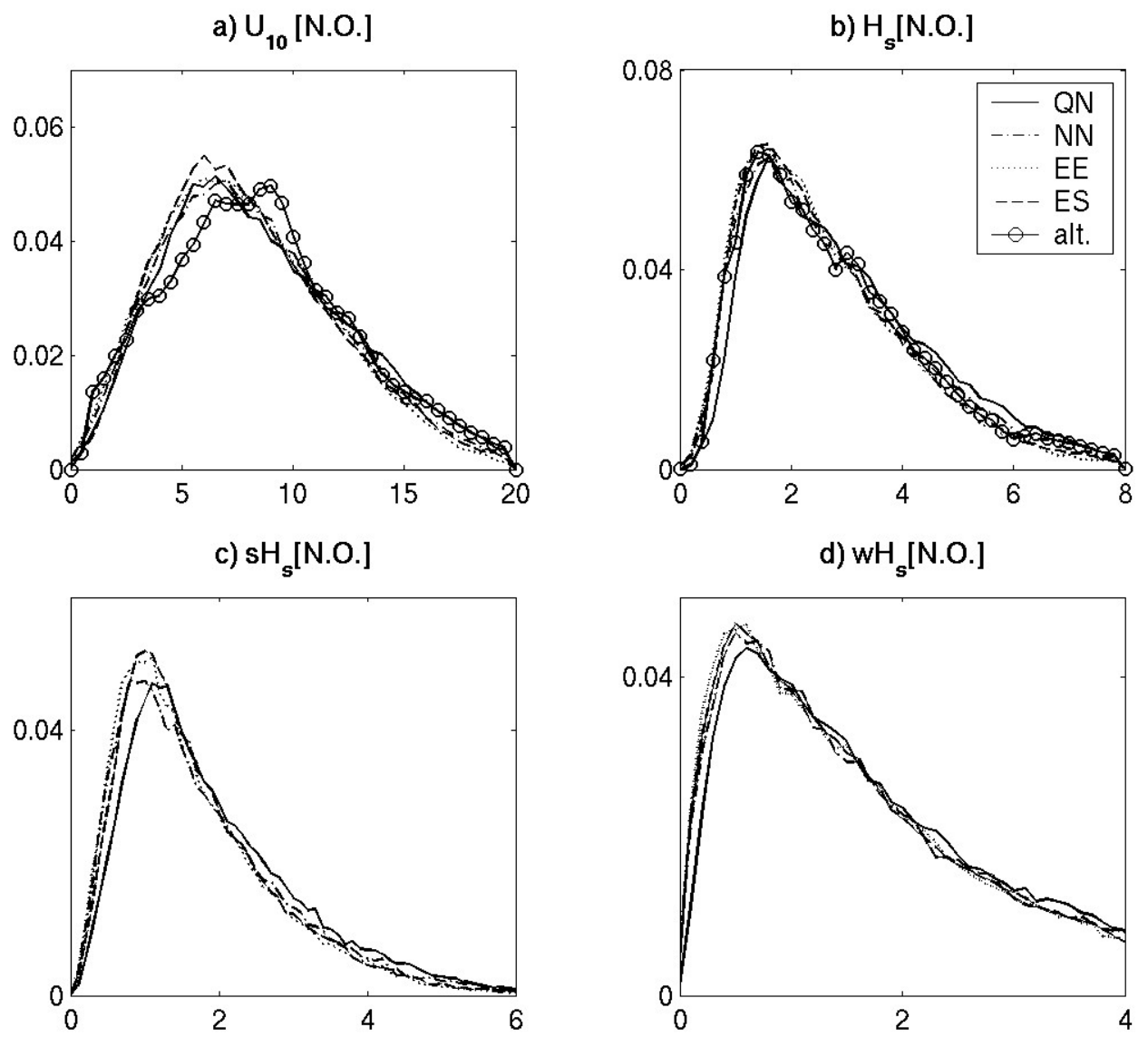

e) $T_{z}$ [N.O.]
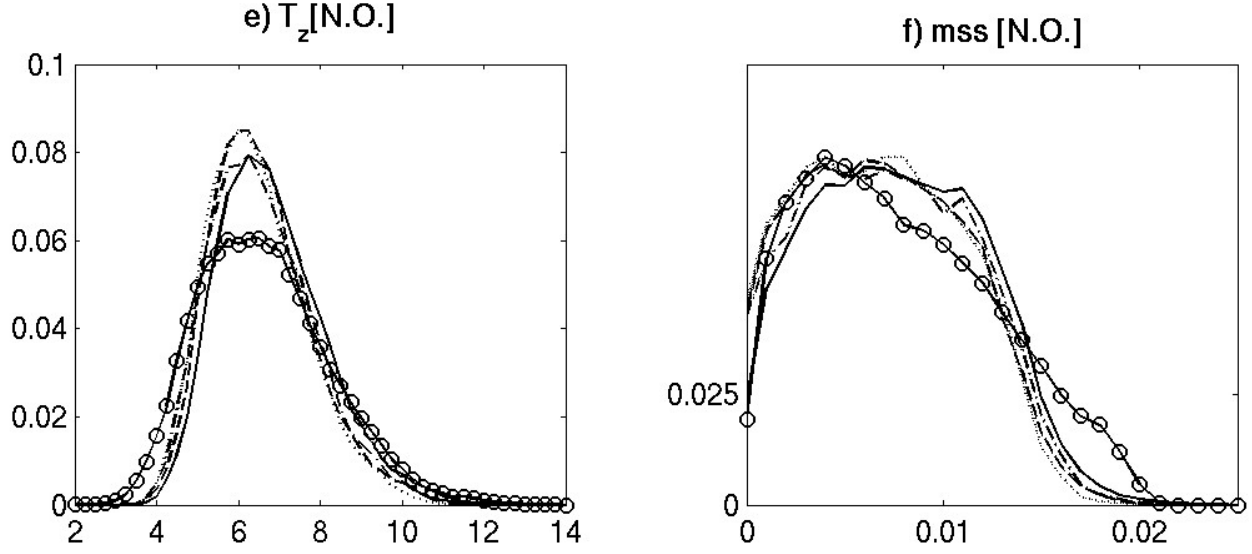

Fig. 6. Validation and comparison of the distributions of the six wind wave parameters (Northern Oceans). All other aspects are the same as in Figure 5. 
a) $U_{10}$ [E.E.P.]
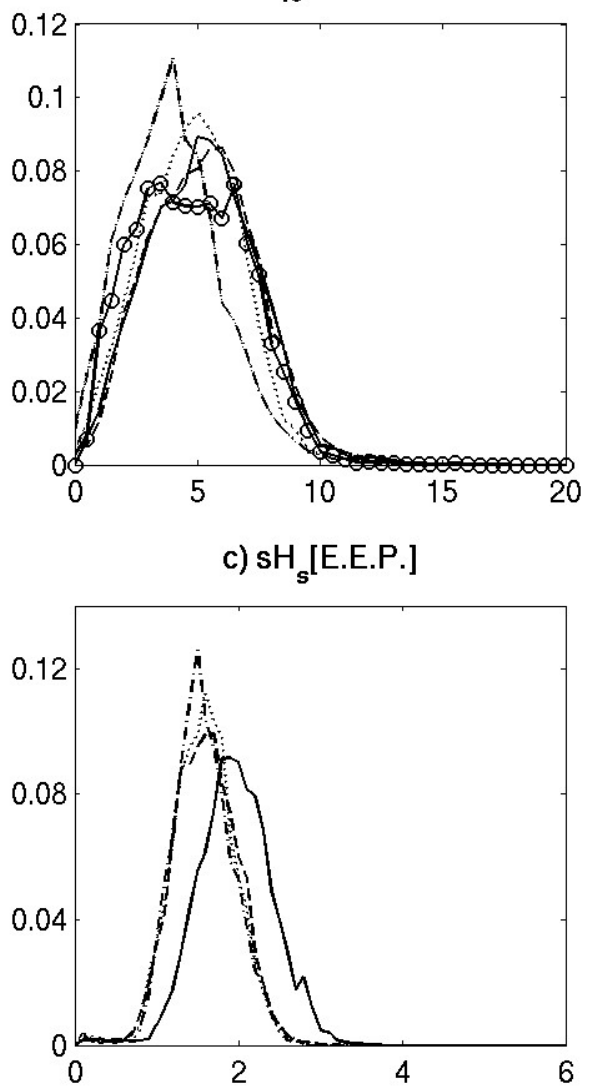

e) $T_{z}$ [E.E.P.]

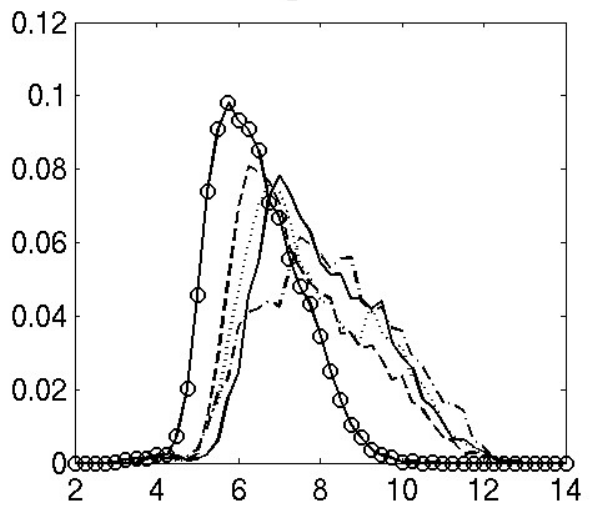

b) $\mathrm{H}_{\mathrm{s}}$ [E.E.P.]
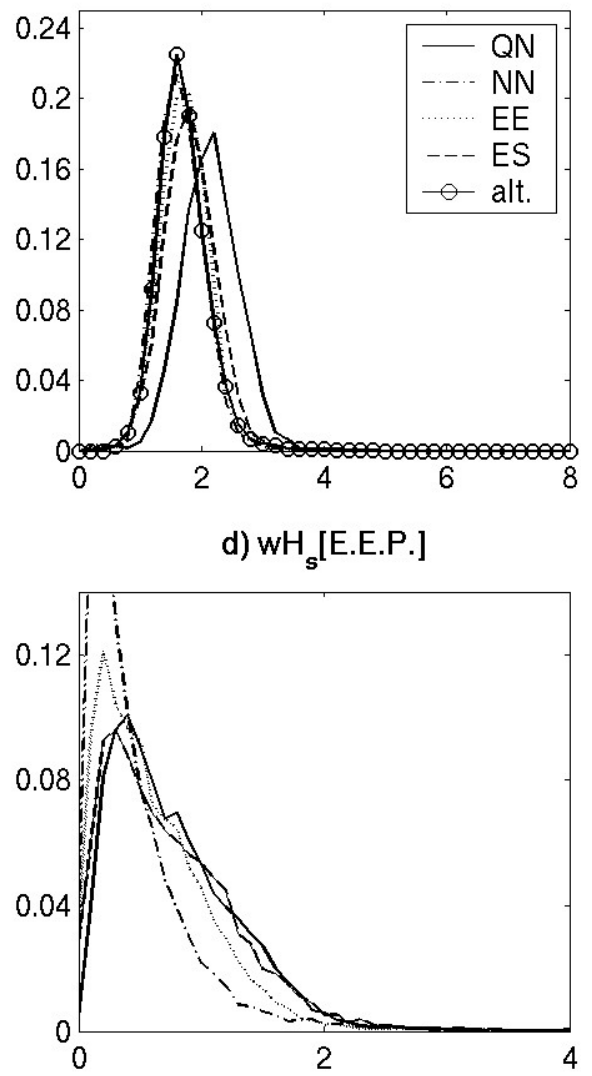

f) mss [E.E.P.]

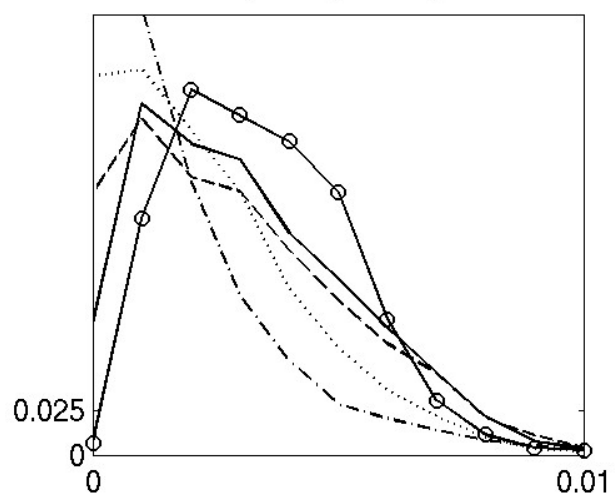

Fig. 7. Validation and comparison of the distributions of the six wind wave parameters (Eastern Equatorial Pacific). All other aspects are the same as in Figure 5. 
a) Bias for $U_{10}$ [Global]

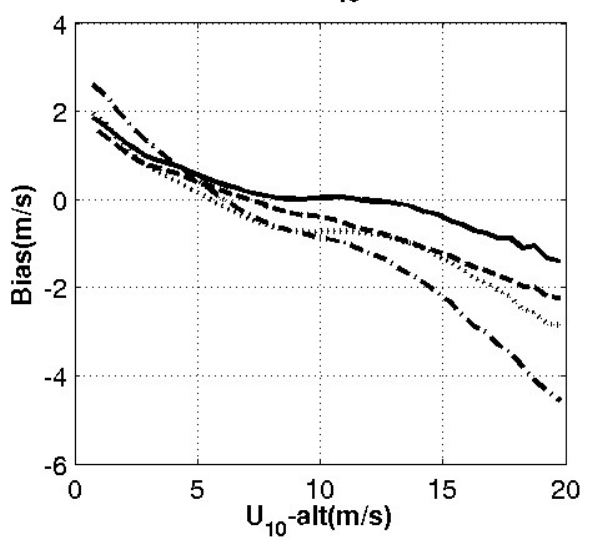

c) Bias for $U_{10}$ [N.O.]

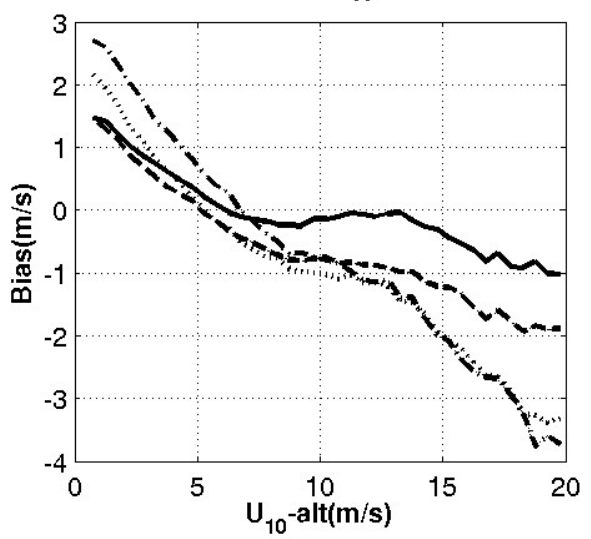

e) Bias for $U_{10}$ [E.E.P.]

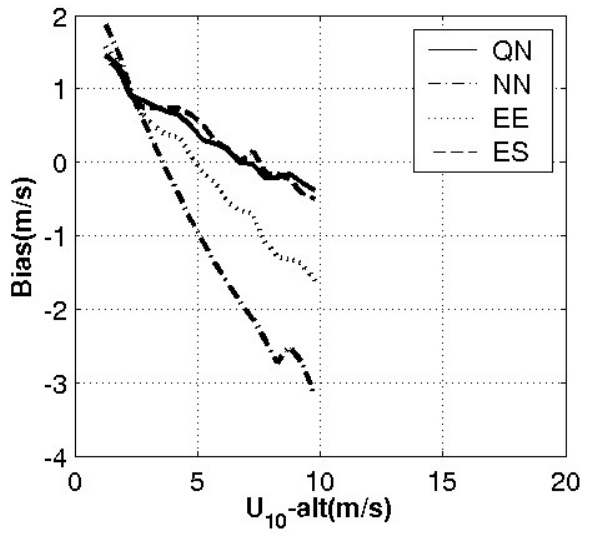

b) $\mathrm{SI}$ for $\mathrm{U}_{10}$ [Global]

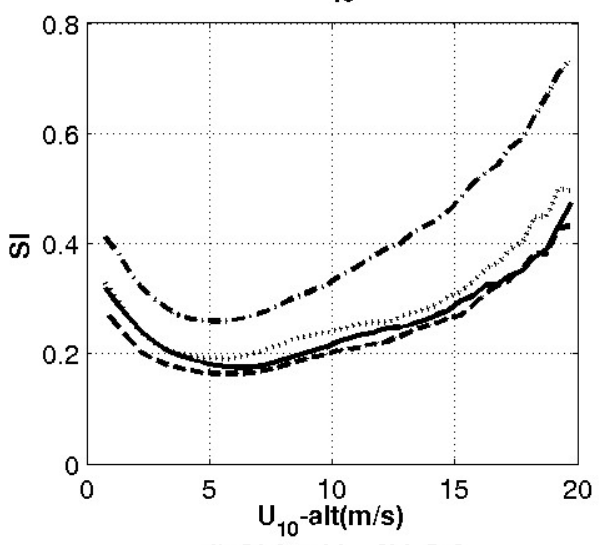

d) $\mathrm{SI}$ for $\mathrm{U}_{10}$ [N.O.]

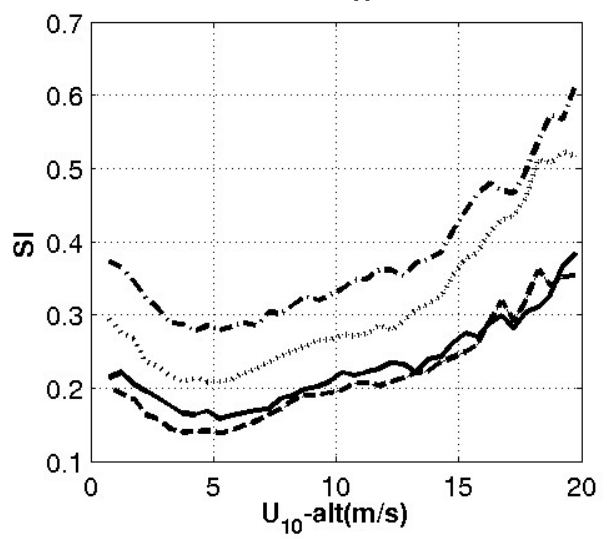

f) $\mathrm{SI}$ for $\mathrm{U}_{10}$ [E.E.P.]

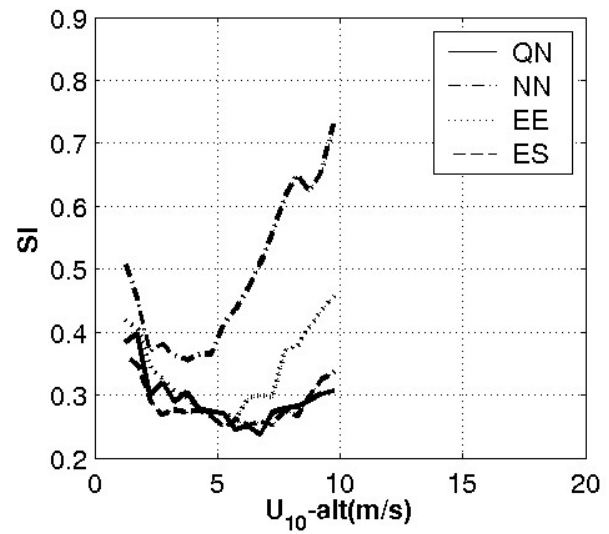

Fig. 8. Plots for the wind speed $U_{10}$ bias (the left column panels) and scatter index (the right column panels) obtained for data bins with respect to the TOPEX-observed $U_{10}$. Solid, dash-dot, dot and dash lines stand for the QuickScat/NCEP (QN), NCEP/NCAR(NN), ECMWF/ERS (EE) and ECMWF/SSMI (ES) winds, respectively. The top, middle, and bottom two panels (a-b, c-d, and e-f) are for the Global, Northern oceans and East Equatorial Pacific regions, respectively. 
a) Bias for $\mathrm{H}_{\mathrm{s}}$ [Global]

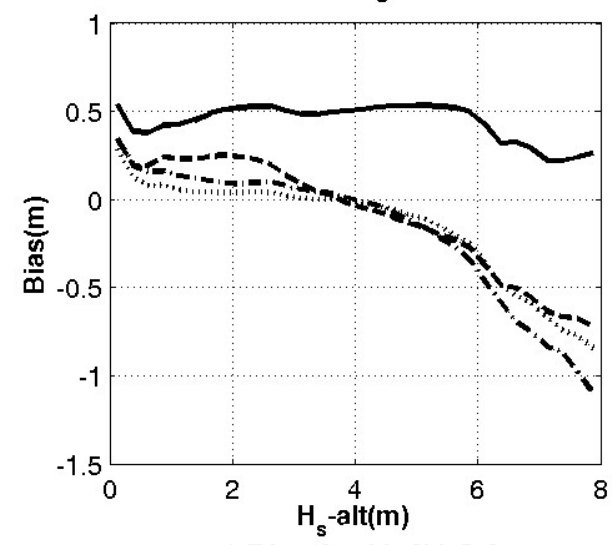

c) Bias for $\mathrm{H}_{s}$ [N.O.]

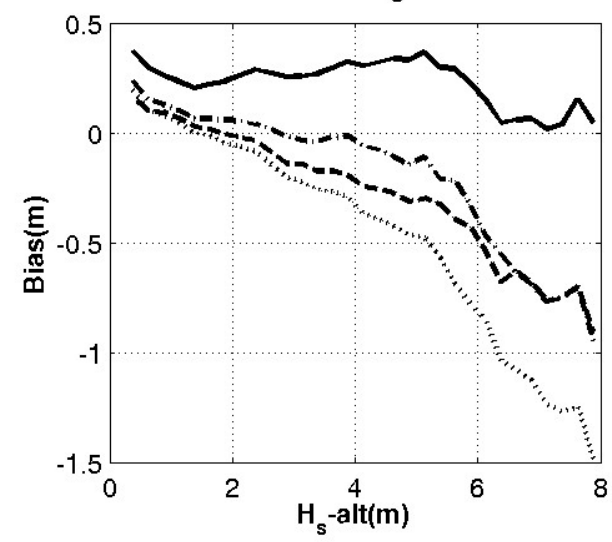

e) Bias for $\mathrm{H}_{s}$ [E.E.P.]

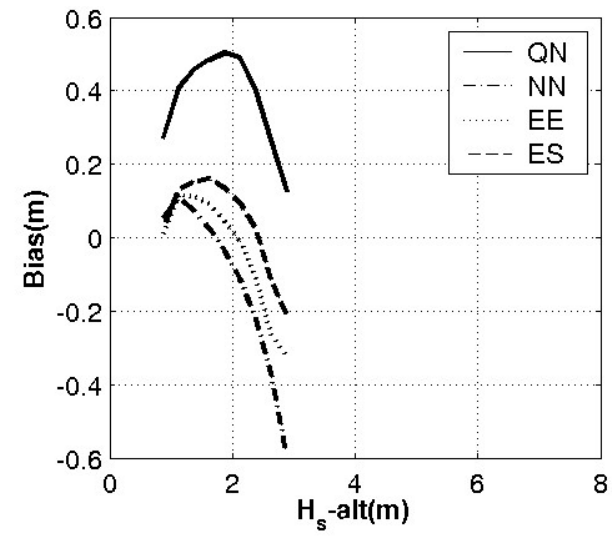

b) $\mathrm{SI}$ for $\mathrm{H}_{\mathrm{s}}$ [Global]

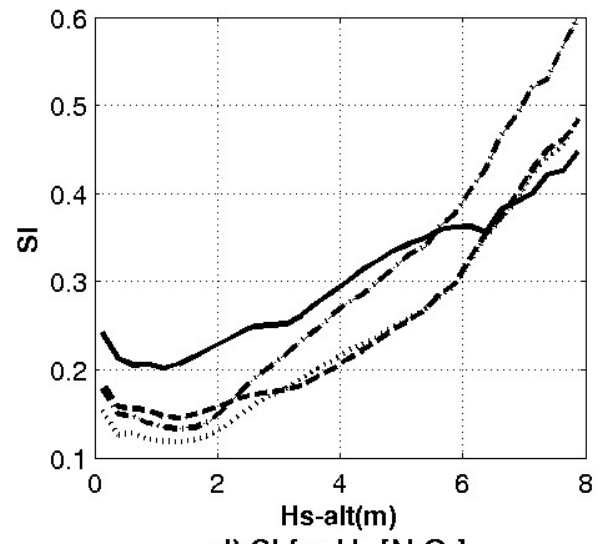

d) $\mathrm{SI}$ for $\mathrm{H}_{\mathbf{s}}$ [N.O.]

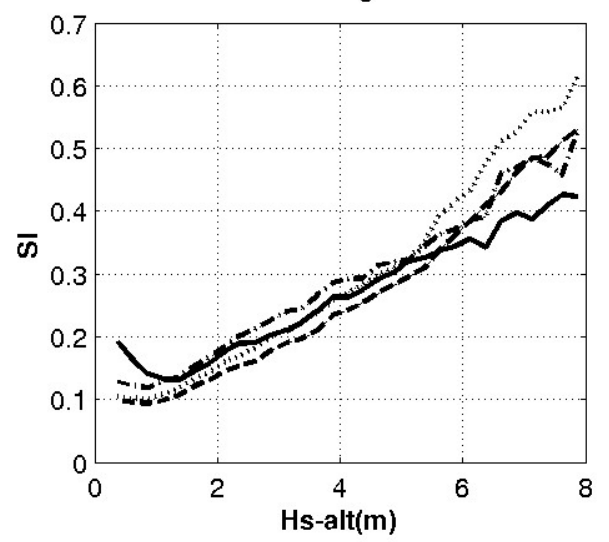

f) $\mathrm{SI}$ for $\mathrm{H}_{\mathrm{s}}$ [E.E.P.]

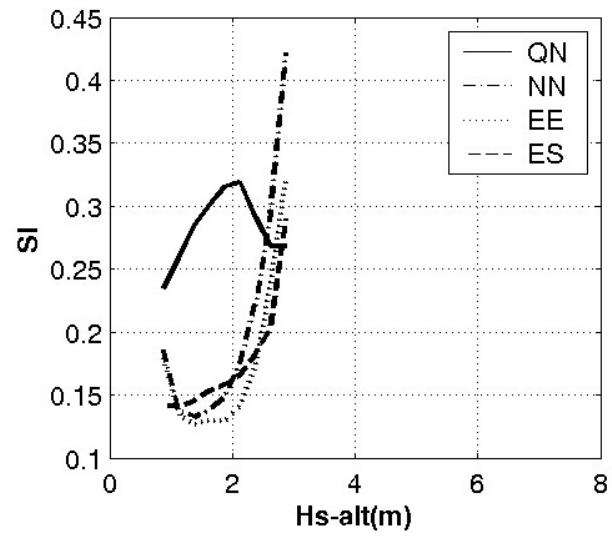

Fig. 9. Plots for the WW3 wave height $H_{s}$ bias (the left column panels) and scatter index (the right column panels) obtained for data bins with respect to the TOPEX-measured $H_{s}$. All other aspects are the same as in Figure 8. 

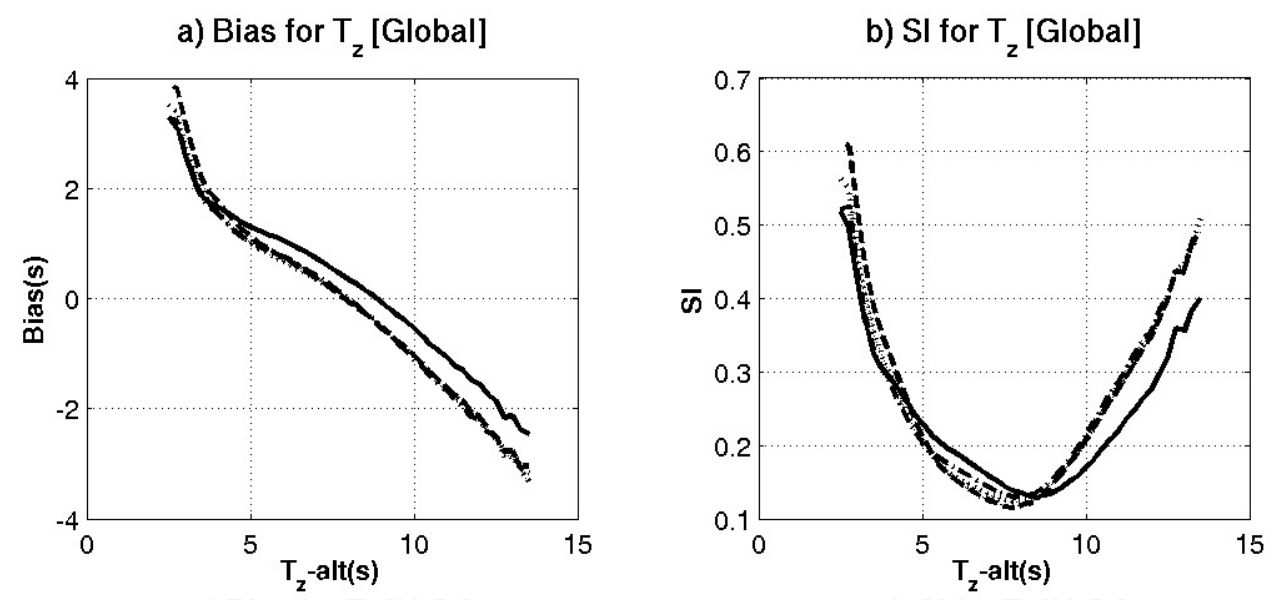

c) Bias for $T_{z}$ [N.O.]

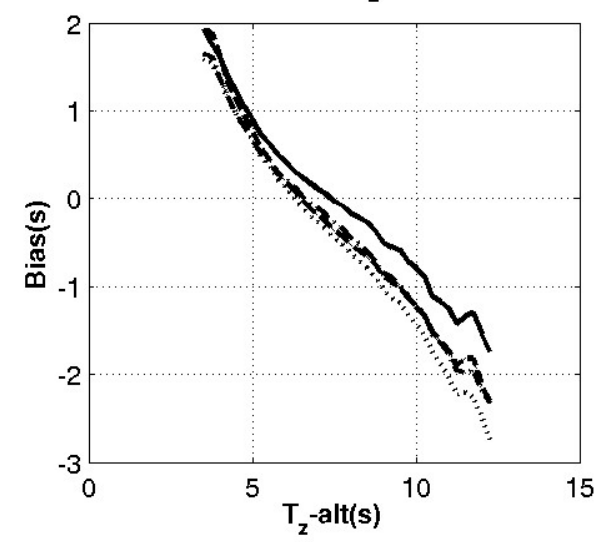

d) SI for $\mathrm{T}_{z}$ [N.O.]

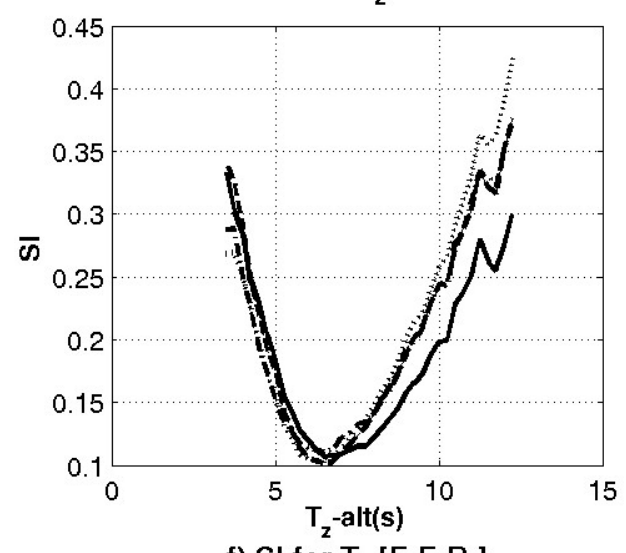

e) Bias for $T_{z}$ [E.E.P.]
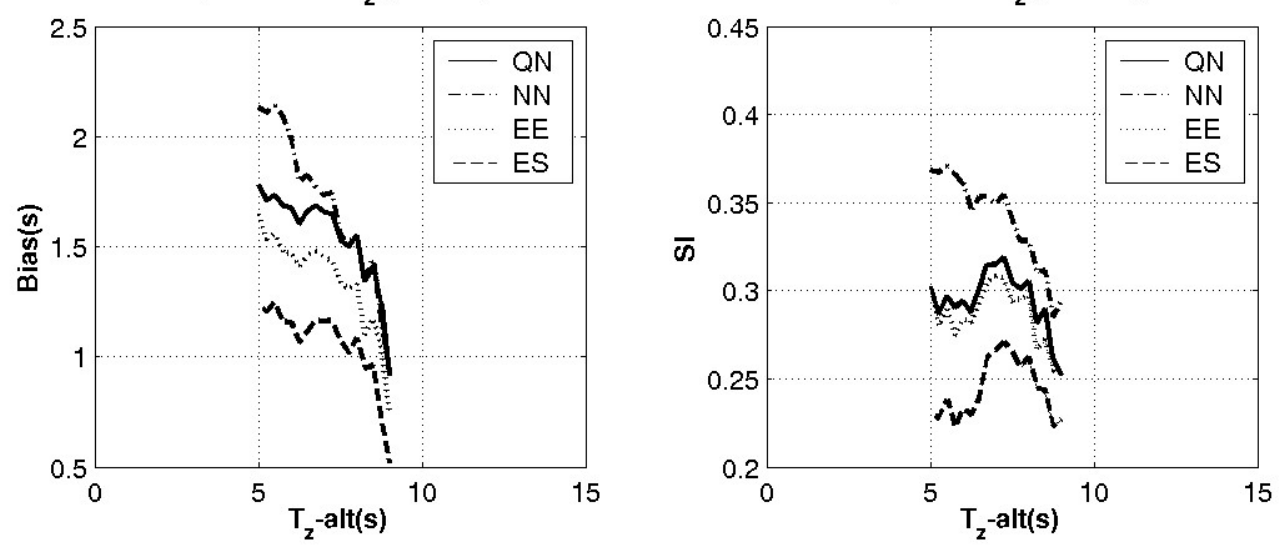

Fig. 10. Plots for the WW3 zero-crossing wave period $T_{z}$ bias (the left column panels) and scatter index (the right column panels) obtained for data bins with respect to the TOPEX-measured $T_{z}$. All other aspects are the same as in Figure 8. 

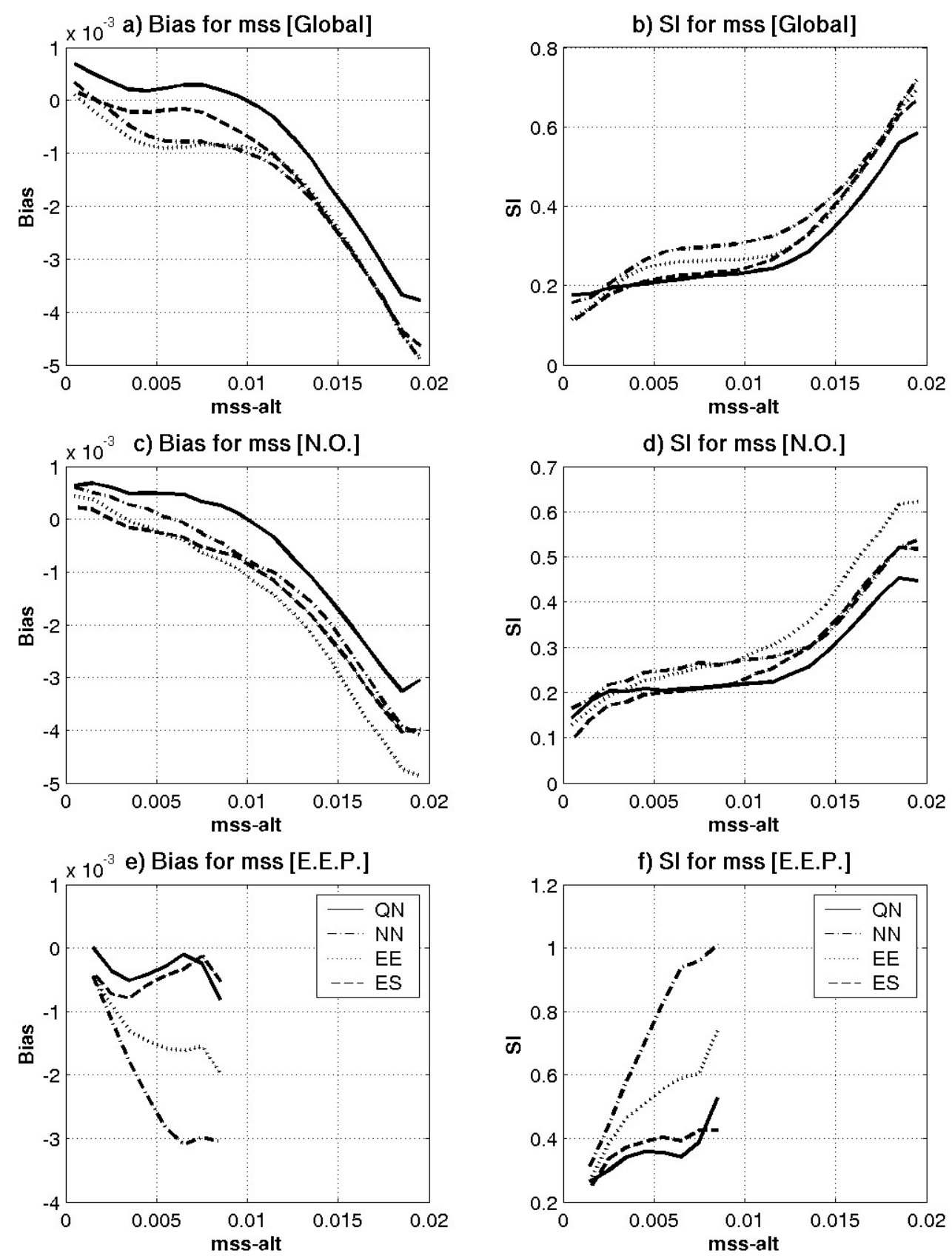

Fig. 11. Plots for the WW3 mean square slope mss bias (the left column panels) and scatter index (the right column panels) obtained for data bins with respect to the TOPEX-measured mss. All other aspects are the same as in Figure 8. 

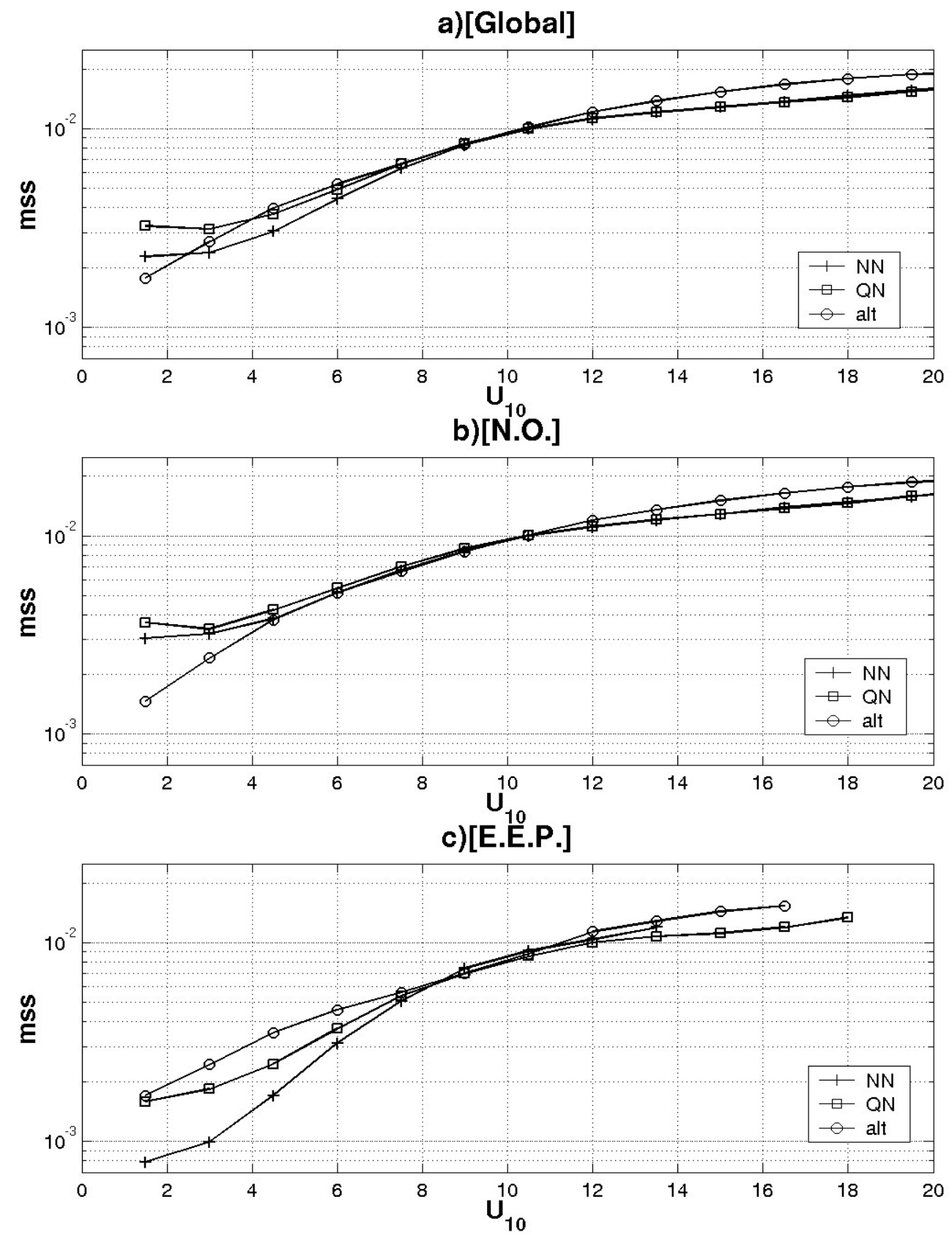

Fig. 12. Wind dependence of the mean square slope mss: a) for the Global; b) for the Northern Oceans and c) for the Eastern Equatorial Pacific. Note that the corresponding wind fields were used in this analysis. 
a) Relative range bias

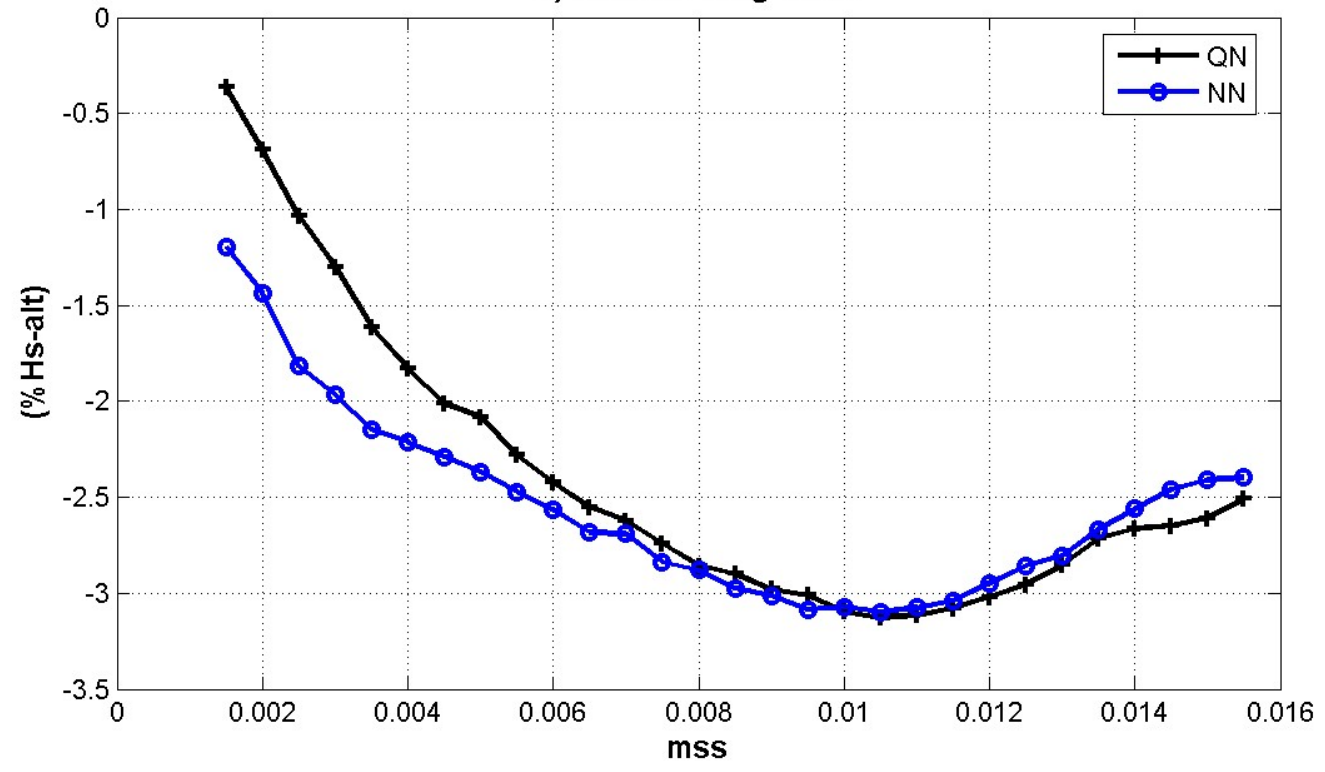

b) Relative bias range difference ( QN minus NN)

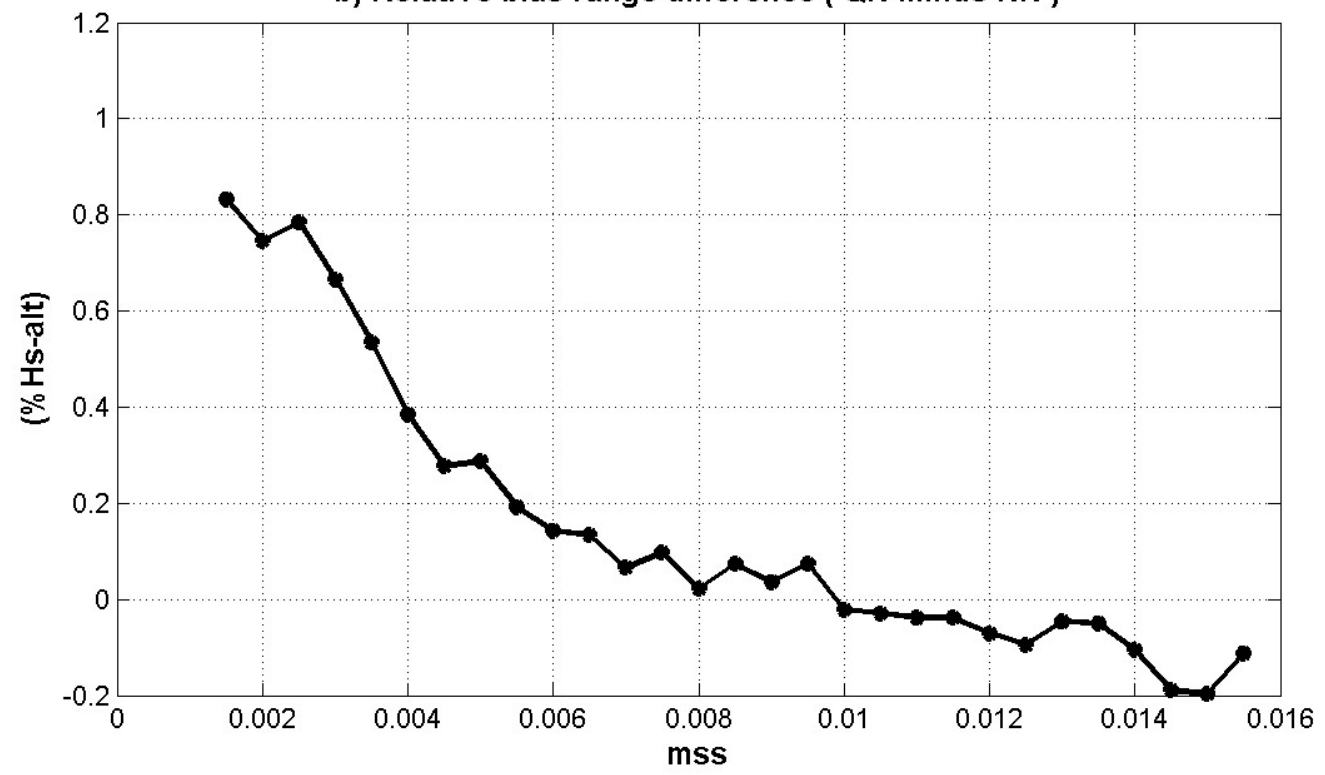

Fig. 13. (a) Binned TOPEX measured relative range bias (i.e. $\beta=s s h a / H_{\text {salt }}$ ) in $\% H_{\text {salt }}$ versus model mean surface slope mss for the global dataset (both WW3-QN and WW3-NN mss are shown for comparison; and (b) the difference in the relative range bias $\beta$ versus WW3-QN mss and versus WW3-NN mss. 